\title{
mrel1S-a yeast mutation that blocks double-strand-break processing and permits nonhomologous synapsis in meiosis
}

\author{
Knud Nairz ${ }^{1}$ and Franz Klein ${ }^{2}$ \\ Institut für Botanik, Abteilung für Zytologie und Genetik, 1030 Vienna, Austria
}

\begin{abstract}
During meiotic prophase the repair of self-inflicted DNA doublestrand break (DSB) damage leads to meiotic recombination in yeast. We employed a genetic screen to specifically characterize cellular functions that become essential after this DSB formation. As a result a new allele of MRE11, termed mrel1S (for Separation of functions) was isolated that allows initiation but not processing and repair of meiotic DSBs similar to the well-characterized rad50S allele. In contrast, the mrell-1 allele blocks initiation of meiotic DSBs as reported previously by others. The mrells allele, which is mutated in the 5 ' part of the gene, can partially complement mrell alleles disrupted close to the $3^{\prime}$ end that cannot initiate DSBs when homozygous. This suggests homodimerization of the Mrell protein and the presence of separate domains for DSB initiation and $5^{\prime}$ resection. The fact that two genes, RAD 50 and MRE11, required for DSB processing are also essential for DSB initiation dictates a model in which a bifunctional initiation/repair complex is required to initiate meiotic recombination. A subset of mrells nuclei was shown to perform extensive but partially nonhomologous synapsis. We propose that the unprocessed DSBs present in mrellS allow for synapsis, but that homologous synapsis is only ensured at a later stage of recombination.
\end{abstract}

[Key Words: M eiosis; synaptonemal complex; MRE11; recombination; DN A double-strand breaks; Saccharomyces cerevisiae]

Received M arch 7, 1997; revised version accepted July 7, 1997.

All sexually reproducing organisms rely on a specialized cell division called meiosis to ultimately produce gametes for conjugation. During this unique process a single round of DNA replication is followed by two rounds of chromosome segregation, reducing the nucl ear content by half. As a result of an elaborate homology search, sorting, and recombination processes, physical connections between homologs are formed. In yeast at least some of the chromosome sorting precedes the initiation of recombination by DNA doublestrand breaks (DSBs) because pairing of homologous DNA can be observed before DSBs appear and in mutants unable to induce DSBs (Scherthan et al. 1992; Loidl et al. 1994; Weiner and Kleckner 1994). Similarly, hot spots for recombination interact before DSBs are formed, because the degree of their homology was shown to influence the degree of DSB formation (Rocco and Nicolas 1996; Xu and Kleckner 1995). DSB initiation requires the gene products of at least 10 genes, namely SPO 11, MRE11,

${ }^{1}$ Present address: Zoologisches Institut, Universität Zürich, 8057 Zurich, Switzerland.

${ }^{2}$ Corresponding author.

E-MAIL fklein@s1.botanik.univieac.at; FAX +43(1)79794/131.
RAD50, XRS2, MER2, MRE2, MEK1/MRE4, MEI4, REC 104, and REC 114 and, most likely, REC 102 (Alani et al. 1990; Cao et al. 1990; Bhargava et al . 1992; Ivanov et al. 1992; M enees et al. 1992; Johzuka and Ogawa 1995; Ogawa et al. 1995; Rockmill et al. 1995a; Bullard et al. 1996; S. Keeney; N . Leem, N. Satoh, and H. Ogawa, both unpubl.). Recently, evidence has been presented that Spo11p catalyzes DSB formation (Keeney et al. 1997; Bergerat et al . 1997), but the role of the other genes is less clear.

To characterize essential processes in the wake of DSB initiation we performed a mutant hunt for DSB-dependent mei otic lethals. The desired mutants are unable to complete mei osis successfully in a wild-type strain background where meiotic DSBs are initiated. Any meiotic mutant defective in DSB initiation can be rescued by an additional spo13 mutation because such strains undergo only a single mitosis-like meiotic division. spo13 alone, however, cannot rescue a DSB-dependent lethal because the DSBs initiate the defective recombination pathway. In contrast, a spo13 rad50 double mutation blocks both recombination and reductional division and thus restores spore viability to the desi red mutants ( $M$ al one and Esposito 1981). As a result of this mutant screen the 
isolation of a new allele of mrell that unexpectedly caused this phenotype is presented below.

mrell was original ly described as a mutation interfering with meiotic recombination (Ajimura et al. 1993). mrell mutants produce dead spores because of a lack of meiotic recombination, but an additional spo13 mutation restores spore viability. A hint that MRE11 al so has a role after DSB initiation came from the fact that a temperature-sensitive mutant entering meiosis at permissive temperature was unable to repair some of the breaks when shifted to restrictive temperature (Ogawa et al. 1995). Johzuka and Ogawa (1995) have cl oned MRE11 and have shown that a disruption mutant (mrell::hisG) cannot initiate meiotic DSBs. Consistent with its essential meiotic function MRE11 transcription is highly upregulated during meiosis as expected for a recombination enzyme. During vegetative growth MRE11 is not essential but required for full radio resistance and control of mitotic recombination levels, indicating that $M$ rellp is required for $D N A$ repair. The same functions are dependent on RAD50 and XRS2.

$M$ rellp was shown to interact with itself physically, as well as with Rad50p (Johzuka and Ogawa 1995) by virtue of the two-hybrid system, suggesting that it may act as a heteromultimere in vivo. Recently, Moore and Haber (1996) and Tsukamoto et al. (1996) showed that M rel1p, Rad50p, and Xrs2p play major roles in nonhomologous end joining in mitotic cells. When repair of a HO-induced DSB was studied in a situation where homologous recombination was precluded, mutants in mrel1, rad50, or xrs2 decreased the yield of nonhomologous end joining, whereas most other members of the rad52 epistasis group did not affect the process (M oore and Haber 1996).

Homologs of MRE11 have been identified in various organisms. The human homolog of M rellp was identified by Petrini et al. (1995) and was shown by coimmunopreciptitation to interact with the human homolog of Rad50p (Dolganov et al. 1996). Homologs to MRE11 have also been found in Caenorhabditis el egans, in Mus musculus, and in Schizosaccharomyces pombe, where it is called RAD32 (Tavassoli et al. 1995). rad32 mutants show defects analogous to mrell mutants, namely impaired mitotic DSB repair activity, as well as decreased mei otic recombination and spore viability. Interestingly, a prokaryotic homolog of MRE11, called SbcD was identified from Escherichia coli by sequence comparison (Gibson et al. 1992; Sharples and Leach 1995). SbcC and SbcD proteins were shown to interact physically and to have double-strand exonuclease and singlestrand endonuclease activity in vitro (Connelly and Leach 1996). Both reactions are dependent on chelatable divalent kations like $\mathrm{Mn}^{2+}$, but only the exonucl ease activity relies on ATP while endonucleolytic DNA degradation is ATP independent and can be performed by SbcD alone (J.C. Connolly and D.R.F. Leach, unpubl.). Therefore, SbcD might be the catalytic subunit of the SbcCD complex, which is modulated by SbcC in the presence of ATP. SbcC is homologous to RAD50, both being members of the Smc protein family, which is involved in
ATP-dependent chromosome condensation (Sharples and Leach 1995). The homol ogy of the prokaryotic SbcC / SbcD pair with their eukaryotic counterparts Rad50/ $\mathrm{M}$ rell suggests a nuclease function for the latter complex.

Data presented below show that $M$ rellp, in conjunction with Rad50p, is required for the $5^{\prime}$ resection of meiotic DSBs by a $5^{\prime} \rightarrow 3^{\prime}$ exonucleolytic activity or a single-strand endonucleolytic activity suggesting that M rel1/Rad50 presumably catal yzes this reaction.

\section{Results}

A genetic screen to identify new functions required after initiation of recombination

A screen for mutants in new genes and functions required after initiation of meiotic DNA DSBs was carried out. Such mutants are expected to derail mei osis because meiotic DSBs entail a series of events that require specific functions for their completion. For instance, failure to repair recombination intermediates may lead to missegregation in both meiotic divisions and/or may possibly cause cell cycle arrest by activating a checkpoint. However, the desired mutation is expected to be rescued by the inactivation of both the RAD50 and the SPO 13 gene. Inactivation of the RAD50 gene prevents DSB formation and initiation of mei otic recombination. Therefore chiasmata do not form, which results in subsequent failure of the reductional division. The need for physical connections can bealleviated by an additional spo13 mutation that causes the cells to skip the first mei otic division. The resulting dyads contain diploid spores with viability similar to those from a RAD50 spo13 meiosis (Table 1). Because all potentially lethal DSB-induced events are bypassed in a rad50 spo13 strain, a function of the defined specificity is dispensable.

Figure 1 summarizes the mutant screen. The homothallic strain $\mathrm{Y} 136$ is rad50, ade2, and spo13 but carries SPO 13 on centromere (CEN )-plasmid pTW15 and RAD50 linked to ADE2 on CEN-plasmid p3. Single spores from $\mathrm{Y} 136$ were mutagenized with N-methyl-Nnitro-N-nitrosoguanidine (MNNG) and plated on syn-

Table 1. rad50 is epistatic to mrel1S

\begin{tabular}{llc}
\hline Strain & $\begin{array}{c}\text { Rel evant genotype } \\
\text { (homozygous) }\end{array}$ & $\begin{array}{c}\text { Spore viability } \\
\text { (\%) }\end{array}$ \\
\hline Y9D×2A & spo13 & 31.9 \\
Y401 & rad50 spo13 & 31.9 \\
Y403 & mre11S spo13 & 1.9 \\
Y402 & rad50 mre11S spo13 & 30.0 \\
\hline
\end{tabular}

spo13 lowers spore viability in SK 1 more than reported for other strains (Wagstaff et al. 1982). N o further decrease is found in the spo13 rad50 double mutant, but in a mre11S spo13 double mutant viability is very low in the few spores formed. rad50 is epistatic to mrel1S because viability in the rad50 mre11S spol3 is the same as in rad50 spo13, demonstrating that RAD50 acts upstream of MRE11. Eighty dyads were dissected each. 


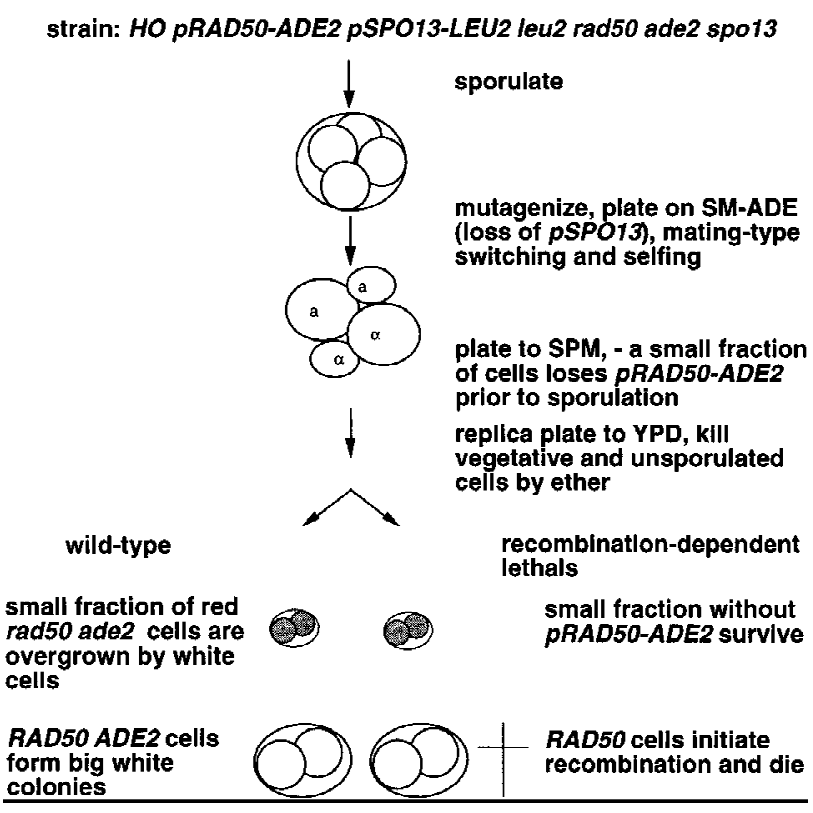

Figure 1. Schematic representation of the mutant screen. Three crucial steps of the protocol for the mutant hunt are illustrated. Spores giving rise to red colonies are shaded, and dead spores are marked by a cross.

thetic complete medium lacking adenine (SC-ADE). For mutagenesis, MNNG was preferred over ethylmethane sulfonate (EMS) because mutations are "fixed" immediately (Klein et al. 1990). Shortly after germination HOinduced mating-type switching leads to diploidization, rendering all mutations homozygous and thereby eliminating mutants defective in mating-type switching (such as rad52). During subsequent proliferation on SC-ADE only plasmid p3 was sel ected for resulting in loss of plasmid pTW15. After 2 days colonies were transferred to sporulation medium (SPM ${ }^{+}$; see M aterials and M ethods), where cells grew for several generations without selective pressure for any two plasmids before they sporulated.

For wild-type cells, the presence of the two plasmids does not interfere with spore viability. Colonies derived from spores of such cells are white, owing to the relative stability of the CEN-vectors and the slow growth of ade2 rad50 cells. In a mutant of the required specificity, however, only cells that lack both plasmids are able to complete meiosis successfully, giving rise to red colonies. After 2 days on SPM ${ }^{+}$, colonies were replica plated to rich medium and were exposed to ether to kill unsporulated cells that would otherwise cause a white background. Predominantly red colonies were scored as potential mutants.

One mutant candi date was chosen for further investigati on because it displ ayed a strong phenotype and cytological examination suggested that synapsis of axial elements was reduced. We cloned the affected gene by complementation of the spore lethality phenotype (see $M$ aterials and Methods), identifying MRE11 as the re- sponsible element. Because MRE11 had been described as being required for DSB initiation (Ajimura et al. 1993; Johzuka and Ogawa 1995; Ogawa et al. 1995) we were surprised to find that MRE11 al so functions downstream of RAD50. The mrell null mutant does not initiate meiotic recombination as a rad50 null mutant does and therefore is predicted to ultimately form white colonies in our assay. The allele described here leads to a lethal event in spo13 cells that initiates meiotic recombination. Because this indicates that the newly identified mrell allele is partially functional and because of the similarity of the phenotypes caused by this allele and by rad50S (Alani et al. 1990) it is referred to as mrel1s.

\section{Isolation of mrel1S, a new non-null allele of M RE11}

We cloned the mrel1S allele by gap repai $r$ and sequenced it. The sequence of the open reading frame (ORF) recovered from the mutant differed from the sequence of the complementing plasmid at positions +250 and +563 (both C $\rightarrow T$ transitions), which predicts a proline-to-serine change at position 84 and a threonine-to-isoleucine change at postion 188 of the protein (Fig. 2).

Several other differences to the reported sequence (Johzuka and Ogawa 1995) were found in both the complementing wild-type clone and the mutated al lele, including a frameshift rendering the predicted protein 49 amino acids longer (to equal 692 amino acids). This carboxy-terminal tail is especially rich in arginine and lysine, as well as serine and threonine, and has a potential nuclear localization site. Two potential coiled-coil domains that span positions 326-351 and, with less likelihood, 506-526 were detected (see Materials and Methods). As mentioned previously by Sharples and Leach (1995) the amino terminus exhi bits homology to the bacterial SbcD recombination enzyme. The region between Pro-63 and Pro-117 contains several amino acids, including Pro-84, which are conserved throughout the eukaryotic homologs known to date. However, it is devoid of any detectable homology to $\mathrm{SbcD}$ while being surrounded by modules well conserved from bacteria to human. The change from Thr to lle at position 188, which is the second mutation contributing to the mrells phe notype, is al so located in a conserved eukaryotic domain.

To confirm the epistatic relationship between rad50 and the newly isolated allele of mrell suggested by the result of the screen we investigated spore viability in various spo13 strains by dissection of dyads (Table 1 ). The results clearly verified that rad50 is epistatic to mrells with respect to the spore viability phenotype.

\section{Genetic evidence for homodimerization of Mrellp}

We have generated a set of mrell alleles of various lengths by transposon mutagenesis in $\mathrm{E}$. coli using the bacterial Tn3 (Seifert et al. 1986). The positions of these insertions were mapped by restriction analysis, and disruptions at different sites within the MRE11-ORF were selected for complementation studies (Fig. 3A). Strains with different combinations of mrell alleles were con- 


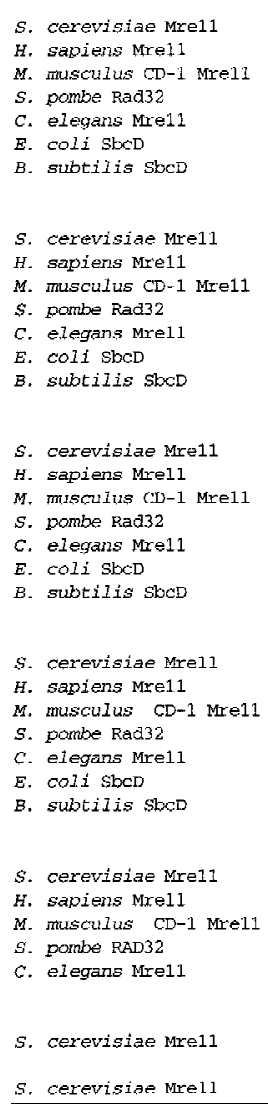

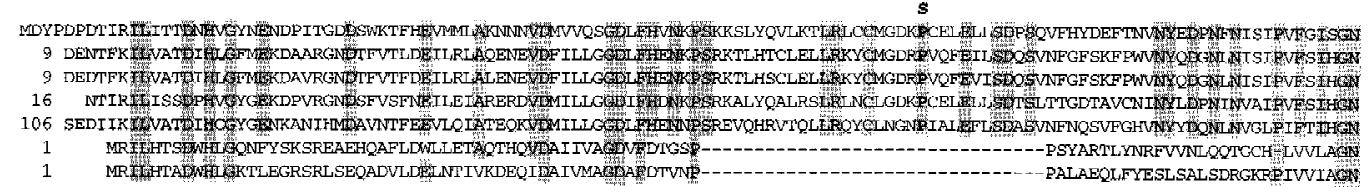

I



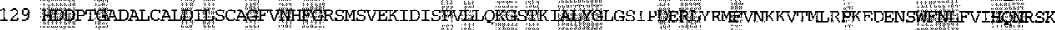

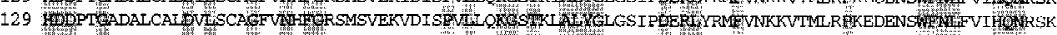

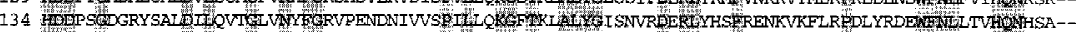

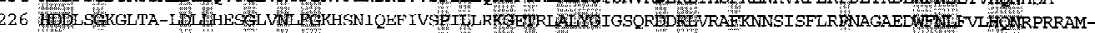



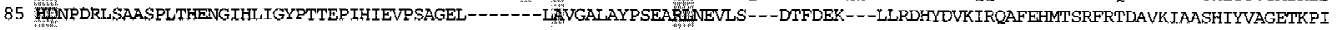

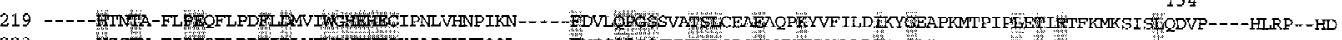

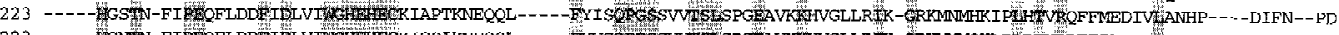

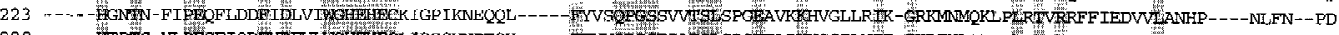

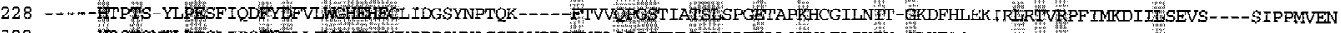

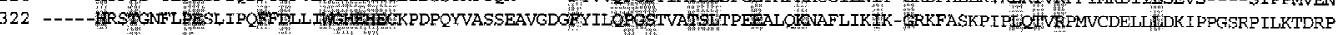

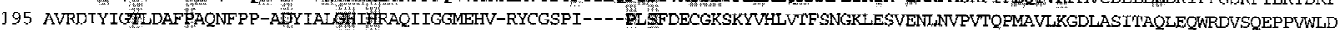

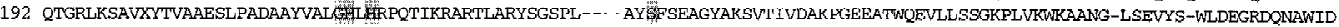
C $c$

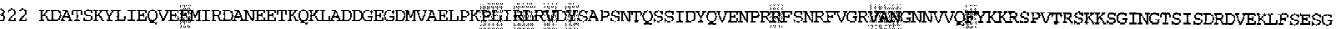

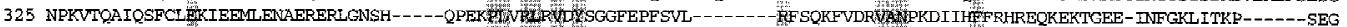

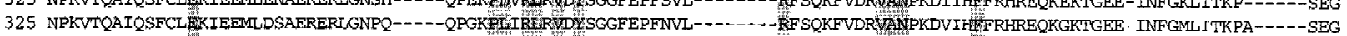

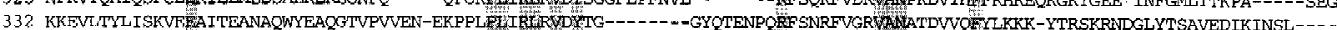

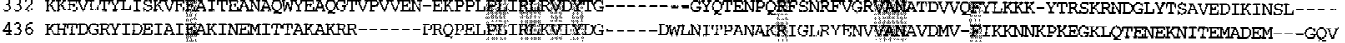
309 IEITT-DEYLFDIORKIOALTESLPVEVLLVRSREQRERVLASQQRETLSELSVEEVFNRRLALEELDESQQQRLQHLFTTTLHTLAGEHEA 306 LEIRVADQLSLEEIHRLRKA

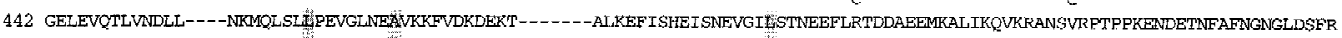

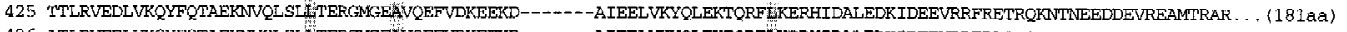



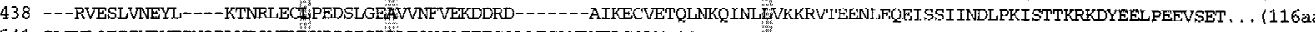

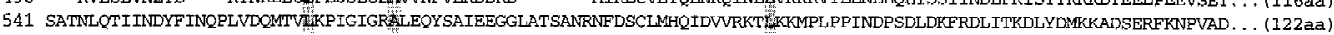

$T 4$

T10

551 SSNREVRTGSPDITQSHVDNESRITHISOAESSKPTSKPKRVRTATKKKIPAF SDSTVISDAENELGENINDAQDEVDIDENDI IMVSIUEEEIASYGLLNGRKTKTKTRSAASTKTASRRG 671 KGRASRTPKTDILGSLLAKKRK

Figure 2. Alignment of predicted Saccharomyces cerevisiae M rell protein sequence with eukaryotic and prokaryotic homologs. Identical amino acids are shaded, $\mathbf{S}$ indicates the site of the proline 84 to serine, and $\mathbf{I}$ the threonine 188 to isoleucine exchange in mrel1S. A potential nuclear localization site is underlined in bold. The first and last amino acids of predicted coiled-coil regions are marked with C. T34, T4, and T10 indicate the approximate transposon insertion sites (see also Fig. 3A).

structed by crossing one mrel1S strain to various partners harboring MRE11, mrel1S, or different mrell transposon disruption alleles. The resulting diploids (wild type for all other sporulation genes) were sporul ated for 2 days on solid medium at $30^{\circ} \mathrm{C}$ and tested for formation of viable spores either by patch assay (Fig. 3B) or by tetrad dissection (Table 2).

Comparison between mrel1S/mrel1S and MRE11/ mrells confirmed that mrells is recessive regarding spore formation and spore viability. Allel es disrupted in the 5' part of the MRE11 gene (mrel1-T20 through mrel1-T34) could not complement mrel1S. Such heterozygotes behave similar to a mrells homozygote by showing greatly reduced sporulation. When the rare tetrads produced by these heterozygotes were dissected they exhibited higher spore viability than the mrells homozygote, but because of the low sporulation efficiency the meiotic yield (number of tetrads produced times viable spores) remained low ( $1 \%)$. All homozygous mrel1-T20, mrel1-T4, and mrel1-T10 disruption strains sporulated well, but spores were inviable.

In contrast, disruptions at the $3^{\prime}$ end (mrell-T4, mrel1-T10) lacking different parts of the evolutionary less-conserved carboxyl terminus complemented mrells to al most wild-type levels of both sporulation and spore viability (when sporulated on solid medium). Transposons T4 and T10 generate in-frame mrell-lacZ fusions (Materials and Methods). mrel1-T40 and mrellT16, which map to the same positions and are equally oriented as mrel1-T4 and mrell-T10, respectively, but are out-of-frame, complemented al so (Fig. 3). $\mathrm{N}$ one of the di srupted mrell al lel es produced a significant number of viable spores when homozygous (Table 2 ). Thus, there is intragenic complementation between mrel1S and the $3^{\prime}$ disruptions.

T wo-hybrid studies by Johzuka and Ogawa (1995) have al ready shown that M rellp can interact with itself. Our results are compatible with this finding and suggest that there is homodimerization while the proteins are active. Homozygous mrells strains or strains heterozygous for mrells and 5' mrell disruptions show strongly reduced tetrad formation, which is similar to the situation in rad50S, a partially functional allele of RAD50 that blocks meiotic DSB processing and repair (Alani et al. 1990). When the two point mutations of mrells were tested separately by dissection, each conferred a strong sporulation and spore viability defect (data not shown).

If the different combinations of mrell alleles behaved 
Figure 3. Intragenic complementation between mrel1S and $3^{\prime}$ truncated alleles. (A) Transposon insertion sites at the MRE11 locus. Arrows point in the direction of the lacZ ORF, and the name of the allele is given. Asterisks and $\mathrm{S}$ and I indicate the sites of the mrells mutations. Transposon insertions mrell-T4 and mrel1-T10 are in-frame lacZ fusions. (B) Patch assay to study intragenic complementation between mrells and the various transposon insertion alleles. Complementation is apparent for MRE11/mrel1S and to a high extent for heterozygotes involving mrel1-T4, mrell-T10, mrellT40, and mrel1-T16. Scarce colonies arising in the mrells homozygote and other heterozygotes may represent few viable spores or vegetative cells surviving ether treatment.
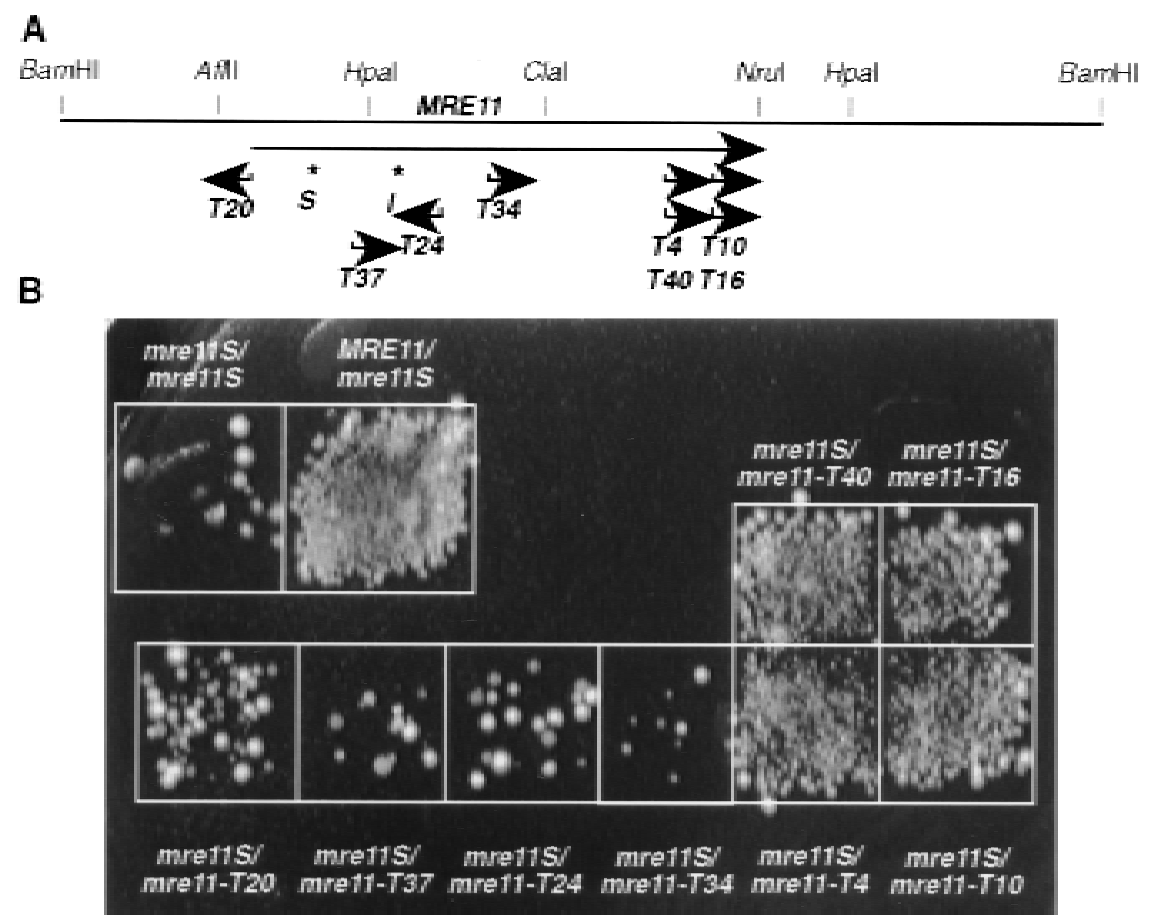

differently in DSB formation, this could result in different levels of induction of meiotic gene conversion. For meiotic mutants induction of meiotic gene conversion can be determined by a return-to-growth experiment (Sherman and Roman 1963), where cells re-enter the mitotic pathway after meiotic induction, but before meiotic chromosome segregation. For some meiotic mutants (e.g., dmc1, zip1), recombination intermediates that would cause a block or even lethal damage to the cells on meiotic medium can be repaired mitotically during return to growth (Bishop et al. 1992; Sym et al. 1993).

We determined meiotic gene conversion between heteroalleles at the artificial his4-LEU 2 and the natural ARG4 recombination hot spots (C ao et al. 1990; Storlazzi et al. 1995) during return to growth. Homozygous mrell-T4 and mrell-T20 strains are unable to induce

Table 2. Different allele combinations of MRE11 fall into three different categories

\begin{tabular}{|c|c|c|c|c|c|}
\hline Relevant genotype & $\begin{array}{l}\text { Unsporulated, } \\
\text { aberrant (\%) }\end{array}$ & $\begin{array}{l}\text { Dyads } \\
(\%)\end{array}$ & $\begin{array}{c}\text { Tetrads } \\
\text { (ttriads) (\%) }\end{array}$ & $\begin{array}{l}\text { Spore viability (\%) } \\
\text { of tetrads (+triads) }\end{array}$ & $\begin{array}{l}\% \text { viability } \times \\
\% \text { tetrads } / 100\end{array}$ \\
\hline MRE11/mrel1S & 39 & 4 & 57 & 96 & 55 \\
\hline mrel1S/mrel1-T10 & 52 & 22 & 26 & 75 & 20 \\
\hline mrel1S/mrel1-T4 & 58 & 11 & 31 & 66 & 20 \\
\hline mrel1S/mrel1-T34 & 90 & 8 & 2 & 30 & 0.6 \\
\hline mrel1S/mrel1-T24 & 87 & 9 & 4 & 3 & 0.1 \\
\hline mrel1S/mrel1-T37 & 84 & 11 & 5 & 30 & 1.5 \\
\hline mrel1S/mrel1-T20 & 84 & 9 & 7 & 28 & 2 \\
\hline mrel1S/mrel1S & 73 & 18 & 9 & 1 & 0.1 \\
\hline mrell-T4/mrel1-T4 & 11 & 24 & 65 & $<1$ & $\varangle 0.6$ \\
\hline mrell-T10/mrell-T10 & 31 & 13 & 53 & $<1$ & $\varangle 0.5$ \\
\hline mrell-T20/mrel1-T20 & 30 & 18 & 52 & $<1$ & $\varangle 0.5$ \\
\hline
\end{tabular}

The mrel1S allele in combination with MRE11 or with the complementing $3^{\prime}$ disrupted alleles mrell-T4 and mrel1-T10 exhibited high sporulation as well as high spore viability. Therefore, the sporulation yield [\% spore viability in tetrads (triads) $\times \%$ tetrads (triads)/100] was also relatively high. A value of $>20$ corresponds to viable patches after ether treatment in Fig. 3 . Strains carrying mrel1S combined with other mrell al leles, such as mrel1-T34, had a very low frequency of tetrad formation, but the small fraction of tetrads formed contained relatively many living spores. Interestingly, the homozygous mrellS caused lower spore viability than a combination of mrel1S and a possible null mutation (mrel1-T20). Strains used were the same as in Fig. 3, except for Y 324 as mrel1S/mrel1-T4. mrel1S, mrel1-T4, mrel1-T20, and mrel1-T10 homozygotes were Y 323, Y 327, Y 328, and Y 442 ×Y 262, respectively. Cells were sporulated on plates, and 200 cells were counted each. Asci with microspores or only one spore were classified as aberrant. At least 100 spores were dissected each for the determination of spore viability. 
mei otic recombination, whereas mitotic recombination is increased compared with wild type (Fig. 4A,B). M itotic hyper-recombination has been observed previously in mrel1, rad50, and xrs2 null mutants ( $M$ al one and Esposito 1981; Ivanov et al. 1992; Ajimura et al. 1993). A rad50S strain is committed to about the same low level of mei otic gene conversion, but the mitotic rate remains al most unchanged compared to wild type. This results in a 5- to 10-fold meiotic induction of gene conversion in rad50S, a phenomenon also seen by Prinz et al. (1997). In the homozygote mrel1S, gene conversion is induced considerably stronger than in rad50S (up to 10-fold, Fig. $4 C, D)$. At the ARG 4 site al most wild-type levels of gene conversion could be observed in the mrel1S/mrell-T4 heterozygote thus supporting the notion of intragenic complementation between mrel1S and 3' disruptions. $\mathrm{N}$ o intragenic complementation was seen at the artificial his4-LEU 2 hot spot under these conditions in two experiments (see Materials and Methods). However, when the mrel1S/mrell-T4 heterozygote was sporulated on solid medium, viability was high (71\%) and genetic distance between U RA 3 inserted at his4-LEU 2 and
MAT was reduced only moderately compared with wild type (Table 3). So this strain clearly is proficient for re ciprocal recombination at his4-LEU 2 under proper sporulation conditions. (A homozygous mrel1S strain could not be tested because of I ow spore viability).

Because a mrell null mutant had been shown to be repair deficient (A jimura et al . 1993) we tested the resistance to methylmethane sul fonate (MMS), a DNA-damaging agent that ultimately causes DNA DSBs, of various mrell mutants. Although the MRE11/mrel1S heterozygote behaves like the isogenic wild type, the homozygous mrel1S strain is partially MMS sensitive (Fig. 5). However, compared to the mrell disruptions (even when disrupted at the very $3^{\prime}$ end as in mrel1-T4), it is remarkably resistant. This is reminiscent of the situation in a rad50S mutant, where repair during vegetative growth is much less affected than meiosis (Alani et al. 1990). When the two point mutations in mrel1S were tested separately, each exhibited MMS sensitivity be tween wild type and mrells (data not shown). As for spore viability, intragenic complementation was al so observed for MMS resistance, because the $3^{\prime}$ disrupted

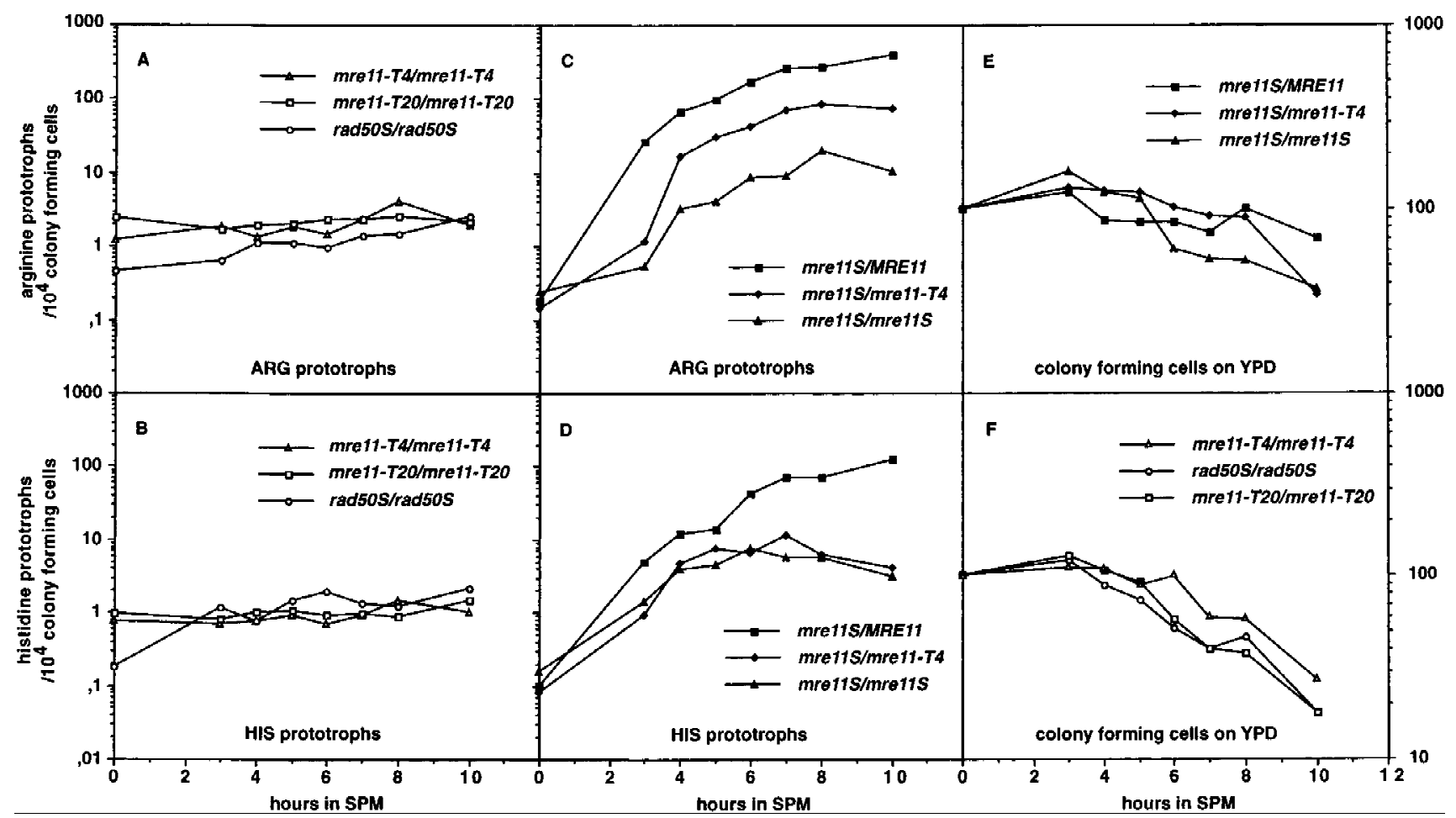

Figure 4. M ei otic recombination can be induced to an intermediate level in the mrellS homozygote and to clearly higher levels for mrellS/mrell-T4 at ARG4. Recombinants are counted as prototrophs on SC-ARG (SC-HIS) per 10,000 colony-forming units (CFU) on YPD. Data were pooled from two independent experiments. $(A, B)$ Gene conversions at two different mei otic hot spots in homozygous mrel1-T4, mrel1-T20, and rad50S strains. M itotic recombination levels can be read at $\mathrm{t}=0$ and are el evated for mrel1-T4 and mrel1-T20. Because mitotic recombination is not altered in the rad50S strain, a 10-fold induction during meiosis is apparent. A similar level of meiotic induction for mrel1-T4 and mrell-T20 would be masked by the recombinants of mitotic origin. (C,D) Gene conversions at two different meiotic hot spots in MRE11/mrel1S, mrel1S/mrellS and mrel1S/mrell-T4 strains. N ormal commitment was observed for MRE11/mrel1S, but was reduced 50-fold for the homozygous mrellS. The heterozygous mrel1S/mrell-T4 was between wild-type and homozygous mrellS at the ARG4 locus but was similar to mrel1S at HIS4. (E,F) Decrease of viability [expressed as CFU (t)/CFU $\left(\mathrm{t}_{0}\right) \times 100$ during progression through meiosis of all strains shown in A-D. 
Table 3. Genetic distance between MAT and URA 3 is significantly reduced in the complementing mrellS/mrell-T4

\begin{tabular}{lcc}
\hline Relevant genotype & $\begin{array}{c}\text { Spore } \\
\text { viability (\%) }\end{array}$ & $\begin{array}{c}\text { Interval } \\
\text { MAT-URA3 (cM) }\end{array}$ \\
\hline MRE11/mrel1S (Y 325) & 97.5 & 45.3 \\
mrel1S/mrel1-T4 (Y 324) & 71 & 29.8 \\
\hline
\end{tabular}

The genetic distance between MAT and URA 3 inserted at the his4-LEU 2 hot spot was determined in 99 complete tetrads of strain Y 324 and 95 complete tetrads of strain Y 325 . The significance of the decrease in recombination rate was $(P<0.025)$ when a $\chi^{2}$ test was performed (Bailey 1995). Strains were sporulated on plates.

mrel1-T4 allele improved viability when heterozygous with mrel1S. Comparing MMS tolerance of mrel1-T4/ mrel1-T4 and the 5' disrupted mrell-T20/mrel1-T20 suggests that mrel1-T4 retains some DNA repair activity, which is in good agreement with its ability to partially complement the mrel1S allele. MMS sensitivity and mitotic hyper-recombination (seen at the $t=0$ point in Fig. 4) seem to correlate, as the homozygous disruptions with the highest MMS sensitivity al so exhibit the highest mitotic level of gene convertants. The same mutants behave like rad50s concerning sporulation (see above).

\section{mrel1S strains accumulate unresected DSBs}

The molecular interaction of Rad50p and M rellp (Dolganov et al. 1996; Johzuka and Ogawa 1995), together with the similarity of rad50S and mrel1S sporulation phenotype, suggested that mrel1S mutants might not be able to process meiotic DSBs (Alani et al. 1990). M eiotic
DSBs were assayed at three different sites, the artificial his4-LEU 2 hot spot (C ao et al. 1990; Storlazzi et al. 1995)(Fig. 6A-D,F-H) as well as at the natural THR4 and DED81 hot spots (de Massy and Nicolas 1993; Goldway et al. 1993) (Fig. 6E). The results show clearly that mrel1S mutants are defective in DSB processing at all sites (Fig. 6A,D,E). N o difference concerning the location of the breakage sites was found for rad50S and mrel1S (Fig. 6C,D). mrel1S is al so recessive to MRE11 concerning the DSB kinetics because one functional allele can restore DSB processing, resulting in a faint, fuzzy band at the 4- and 5.5-hr time points that disappears due to repai $r$ (Fig. 6B). No DSBs could be detected in mrel1-T4 or mrel1-T20 homozygotes at his4-LEU 2, as expected. Thus, although both of these genes seem not to be functional on their own, only mrel1-T20 is a null mutant because the truncated mrel1-T4 still is able to improve viability and recombination when heterozygous with mrells. However, no difference was observed between mrells/mrell-T4 and mrells/mrells concerning accumulation of DSBs at the his4-LEU 2 hotspot (Fig. $6 A, D, H)$, which is consistent with the absence of an effect of mrel1-T4 on induction of meiotic gene conversion at this locus. We attribute the apparent contradiction that mrel1-T4 can partially complement mrel1S when testing for sporulation or MMS sensitivity (solid media), but not when testing for commitment to meiotic recombination and DSB repair at his4-LEU 2 (Iiquid media) to the different conditions used. Also complementation of the spore formation defect only worked when cells were sporulated on plates but not in liquid SPM (data not shown).

Intensities of parental and DSB-induced signals were determined for each lane using a Phosphorlmager. The ratio of DSB versus parental band was used as the parameter to indicate DSB levels. Such quantification reveal ed that at both loci examined more broken DNA molecules
Figure 5. Residual resistance to MMS varies over several orders of magnitude for different diploid mrell mutants. Cells from late exponential phase were plated on YPD containing the indicated amount of MMS and scored after 3 days. Resistance decreased strongly in the strains in the following order except for the first two strains, which were similar: MRE11/ MRE11, MRE11/mrells, mrel1S/mrellT4, mrells/mrells, mrell-T4/mrellT4, mrel1-T20/mrel1-T20. Y 328 (mrel1T20/mrel1-T20) did not form visible colonies after 3 days on plates containing $0.005 \%$ MMS. The symbol at the end of the dashed line therefore marks the lower limit of detection.

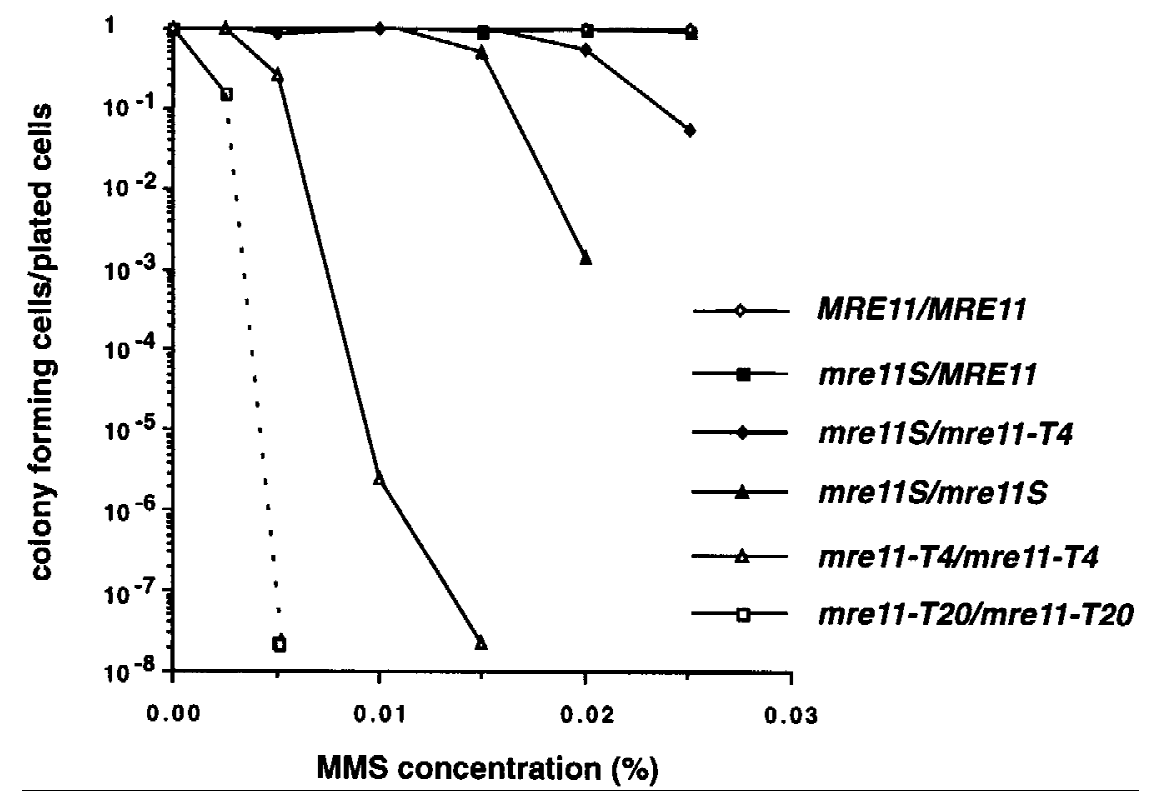


are present at later time points in rad50S(KI81) than in mrel1S mutants, the relative difference depending on the locus (Fig. 6A,E).

Unlike in rad50S the mrel1S DSB signals decrease at the 8.5- and 9-hr time points. If this decrease is attributable to residual single-strand degradation in mrel1S strains (but to a lesser extent in rad50S) and the broken molecules are finally converted to recombination products, this may explain why mrel1S is more inducible for gene conversion than rad50S in return-to-growth experiments.

DSBs also accumulate at another hot spot for recombination-THR4-both in mrel1S and rad50S single mutants, as well as in a rad50S mrel1s double mutant (Fig. 6E). In addition, a com 1 mrel1S mutant was tested (data not shown) and found to yield the same breakage pattern at THR4 as mrel1S and com1/sae2 (M cKee and Kleckner 1997; Prinz et al. 1997) alone.

mrel1S mutants are defective in forming homologous synaptonemal complexes

M utants that can be rescued by spo13 are unable to synapse their axial elements (AEs) (Alani et al. 1990; Engebrecht et al. 1991; Bhargava et al. 1992; Menees et al. 1992; Loidl et al. 1994; Johzuka and Ogawa 1995), whereas mutants that require an additional spoll mutation to produce viable spores were shown to have re duced synaptonemal complex (SC) formation (Alani et al. 1990; Bishop et al . 1992; Loidl et al . 1994; Rockmill et al. 1995b; Prinz et al. 1997). In such mutants AEs much longer than those in wild type have also been observed. In this study a considerable fraction of nuclei showed extensive, al though not wild type-like, synapsis.

To relate DSB formation with a cytological phenotype, synapsis and DSBs were examined in the very same experiment for the MRE11/mrel1S, the heterozygous mrells/mrell-T4, and the homozygous mrell-T4 and mrel1S strains. Nuclei of wild-type and mutant cells were classified as belonging to five categories by their content of SC-related structures visualized in the transmission el ectron microscope (TEM) (Figs. 7A-I and 8AE). One hundred eighty-one to two hundred seventy-five nuclei were counted per time point per strain. The kinetics of SC formation and degradation in the MRE11/ mrel1S heterozygote was as reported for a published wild type, and the kinetics of the mrell-T4 strain was similar to rad50s (Padmore et al. 1991). mrel1S/mrellT4 behaved like mrel1S/mrellS with respect to SC formation, further indicating that intragenic complementation is not very pronounced during sporulation in liquid medium.

Short AEs comprise the first class of nuclei observed in wild type and mutants. However, they can differ, as very thick short AEs were found in nuclei of all mrell mutants but not of wild type. Wild-type nuclei of this class contain typically very faint AEs. Also, the total number of nuclei with short AEs is lower and decreases faster in wild type than in the mutants, indicating that the turnover of these precursors to the next stage is blocked or delayed in the mutants (Fig. 8A-D). The mrel1S/mrel1S and mrells/mrell-T4 strains exhibit a second category

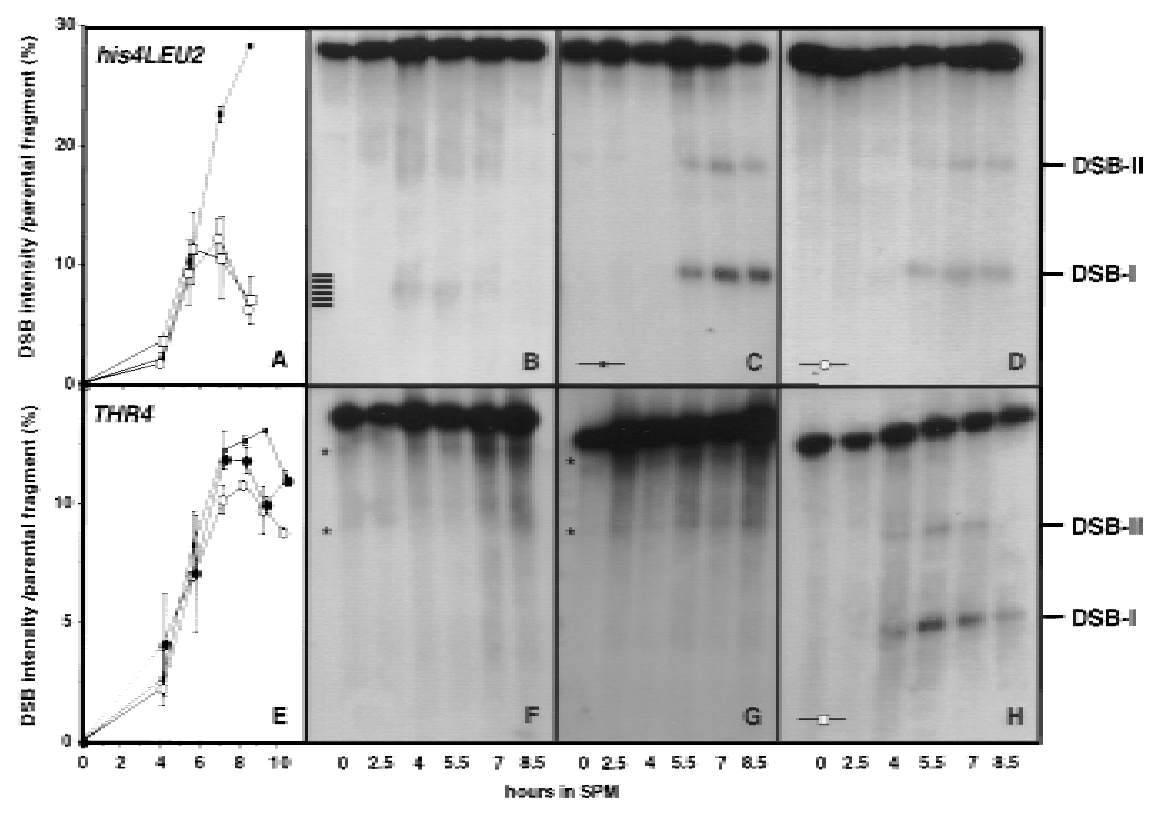
broken DNA at the major DSB site close to THR4 relative to the parental fragment (representation analogous to A). ( $\square$ ) Y 329 (rad50S/rad50S); (O) Y 323 (mrel1S/mrel1S); (•) Y292×294 (mrel1S rad50S/mrel1S rad50S). N o DSBs were detectable in strai ns Y 328 (mrell-T20/mrell-T20) (F) and Y 327 (mrell-T4/mrel1-T4) (G). Asterisks indicate signals corresponding to repetitive DN A on the ethidium bromide-stained gel (not shown; see also Storlazzi et al. 1995). (H) In Y 324 (mrel1S/mrel1-T4) DSB formation was not different from that of mrel1S homozygote (D).

Figure 6. mrells mutants accumulate meiosis-specific unresected DN A DSBs at recombination hot spots. All experiments shown except for $E$, were done at the artificial his4-XLEU 2-Mlul::BamHI/his4BLEU2-Mlul hot spot and blots were hybridized with probe A (pNKY291). DSB-I and DSB-II mark the location of major cleavage sites. (A) Quantification of the amount of broken DNA at site DSB-I at his4-LEU 2 relative to the parental fragment is the result of two independent experiments. The symbols represent the mean value, whereas individual results are symbolized by the error bars. (D) Y 329 (rad50S/rad50S); ( $\square$ ) Y324 (mrel1S/ mrell-T4); (O) Y323 (mrel1S/mrells). One set of data is $C, D$, and $H$. (B) For wild-type strain Y325 (MRE11/mrel1S) processed breaks can be seen as a smear at 4 and $5.5 \mathrm{hr}$. Homozygous rad50S (C) and mrellS (D) strains accumulate unresected DSBs visible as sharp bands in a similar way. (E) Quantification of the amount of 


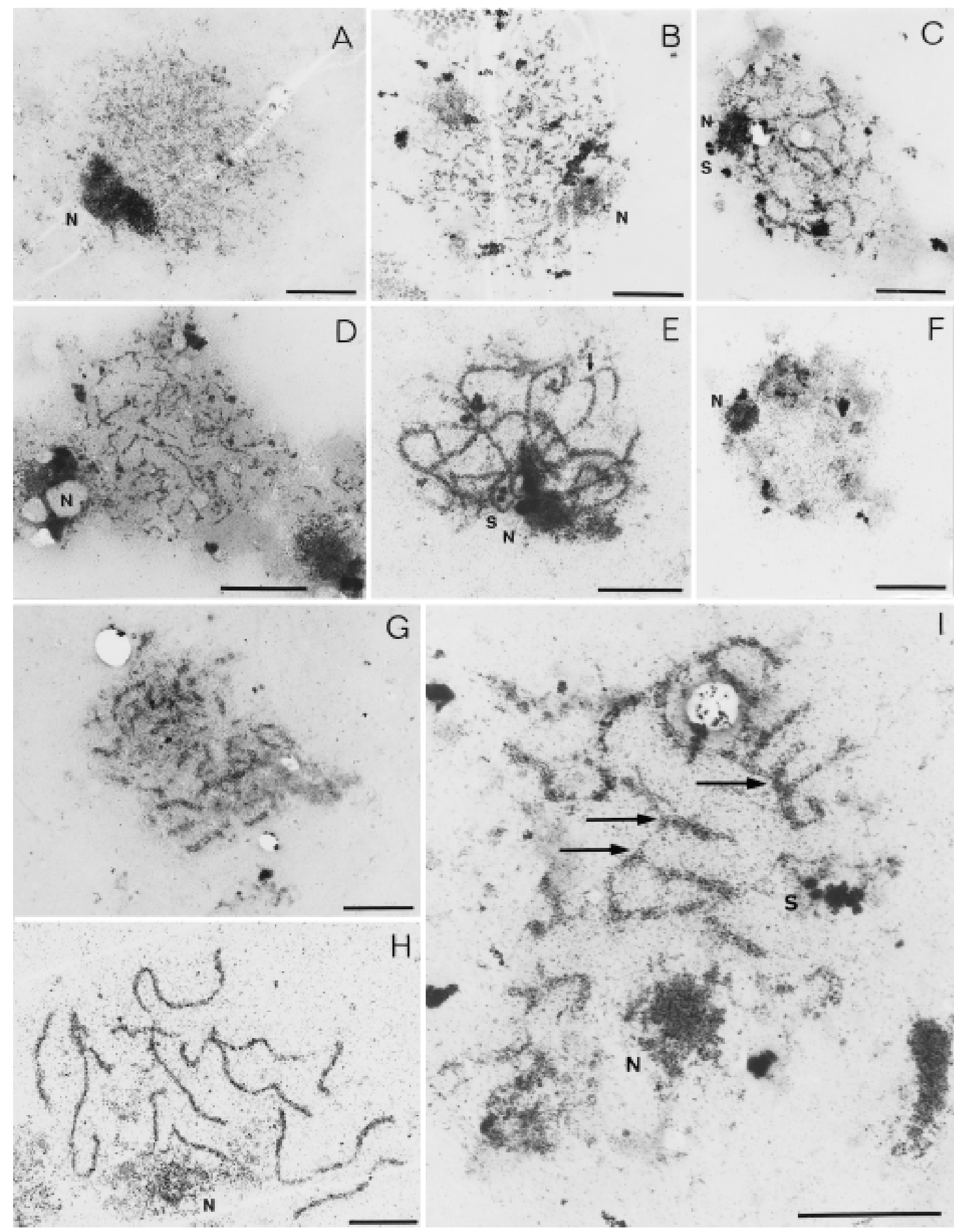

Figure 7. A berrant SC formation in mrell mutants shown by electron microscopy. Examples of nuclei classified according to their SC-related morphology are shown. SCs and their precursors are visible as el ectron dense linear structures, nucleoli (N) as prominent large irregularly shaped dots, and spindle pole bodies (S) as little, round, double spots (bars, 2 um). (A,B) Class 1 nucl ei contai ning short, unsynapsed axial el ements. mrell nuclei sometimes contain sl ightly thickened short axial el ements as in (B); (C) class 2 nuclei contain both short unsynapsed axial elements and partially synapsed stretches; (D) class 3 nuclei containing elongated unsynapsed axial elements were predominantly observed in mrel1S mutants; (E) extensive SC formation (class 4) in a mrel1S/mrel1S nucleus with only few SC ends visible (the arrow marks a potential partner switch); (F) class 5 nucleus devoid of SC structures possibly past prophase; (G) a rare example of SC formation in mrel1-T4 homozygotes; $(\mathrm{H})$ wild-type SCs (class 4) from the MRE11/mrel1S strain; (I) partner switches of axial el ements confer a network-like appearance to some SCs in the mrel1S mutant. Arrows indicate sites of presumed partner switches. A, B, and G are from strain Y 327 (mrell-T4/mrell-T4); C-F and I are from Y 323 (mrells/mrellS) and H is from Y 325 (MRE11/mrel1S). 




Figure 8. Kinetics of class 1-5 nuclei during progression through meiotic prophase. Quantitative analysis of SC-related structures of the time course experiment presented in Figs. 6 and 7. Cells past meiosis I are bi- and tetranucleate as observed after DAPI staining. (A-D) Symbols corresponding to class 1-3 and class 5 nuclei and meiotic progression are described in the upper right panel. (E) For clarity, class 4 nucl ei exhibiting extensive SC s are presented separately. Wild type exhibited up to 30\% SC formation, mrel1S mutants up to $7 \%$, but the mrell-T4 homozygote only $\sim 1 \%$.

of unsynapsed A Es (class 3) that are el ongated and thickened (Figs. 7D and 8B-D). They also have been described for rad50S/rad50S strains (Alani et al. 1990). This class may either exist as a direct consequence of the cell cycle delay in mrel1S cells or, alternatively, represent AEs that were unstably synapsed in vivo, thus belonging to class 2 or 4 (see below), but had been disrupted by the spreading forces. Figure 7C shows an example of a nucleus with both unsynapsed AEs and synapsed stretches (class 2). This class is represented well in $\mathrm{mrel1S} / \mathrm{mrellS}$ and $\mathrm{mrel1S} / \mathrm{mrell}-\mathrm{T} 4$ strains, al beit slightly delayed relative to wild type (Fig. 8A,C,D). This also is interpreted as a consequence of a delay in the progression of one transition state (class 2) to the next (class 4). Class 2 nuclei are very rarely found for mrellT4/mrel1-T4, suggesting a role of DSBs for synapsis (see bel ow). Because synapsing and degrading SCs are sometimes morphologically indistinguishable, we propose that class 2 nuclei contain mainly synapsing SCs before class 4 peaks and mainly degrading SCs after that.

Class 4 nuclei show extensive SC formation but no unsynapsed AEs (Fig. 7E,G-I). However, whereas in wild type there are usually a number of 10-16 discrete complexes corresponding to the paired chromosomes, the mutants give a more variable picture. Figure 7E depicts a mrel1S/mrells nucleus with extensive SC loops, but SC s are not separated from each other. Figure $7 \mathrm{l}$ shows a different mrells/mrells nucleus, where a network of SCs connected via AEs that perform partner switches can be observed. This situation is similar to that decribed earlier for haploids undergoing meiosis (Loidl et al. 1991) indicating that synapsed A Es connect, at least in part, nonhomologous chromosomes. A very rare example of a mrel1-T4/mrell-T4 nucleus with extensive synapsis, showing far more than 16 synapsed entities is shown in Figure 7G. We also observed very small fractions of nuclei forming elongated AEs and showing extensive synapsis (Fig. 8E). We suspect that rare examples of SC formation arise from nuclei initiating some DSBS that are below the limit of detection in our Southern bl ot (Fig. 6G) and in return to growth (Fig. 4A). In general, most of the mrel1-T4 nuclei were only able to form short AEs (Fig. 7B), as expected from a mutant unable to initiate DSBs.

The parallel monitoring of DSB levels and synapsis allows the correlation of these two mei otic landmarks. For the wild type, DSBs reached their maximum level at $4 \mathrm{hr}$. At the same time, first synapsis, but no complete SC, was observed. In the mrellS mutants the first major increase in DSBs is at $5.5 \mathrm{hr}$, which is shortly before or at the time when the first synapsis can be demonstrated.

\section{Both homologous pairing and SC formation are} reduced in mrells

The presence of partner switches in mrell mutants demonstrated by electron microscopy of silver-stained spreads indicated the occurrence of nonhomologous synapsis. We have combined fluorescence in situ hybridization (FISH) and immunocytology in an effort to study synapsis and homologous pairing - to compare the reduction of SC formation in the mutant with the quantity 

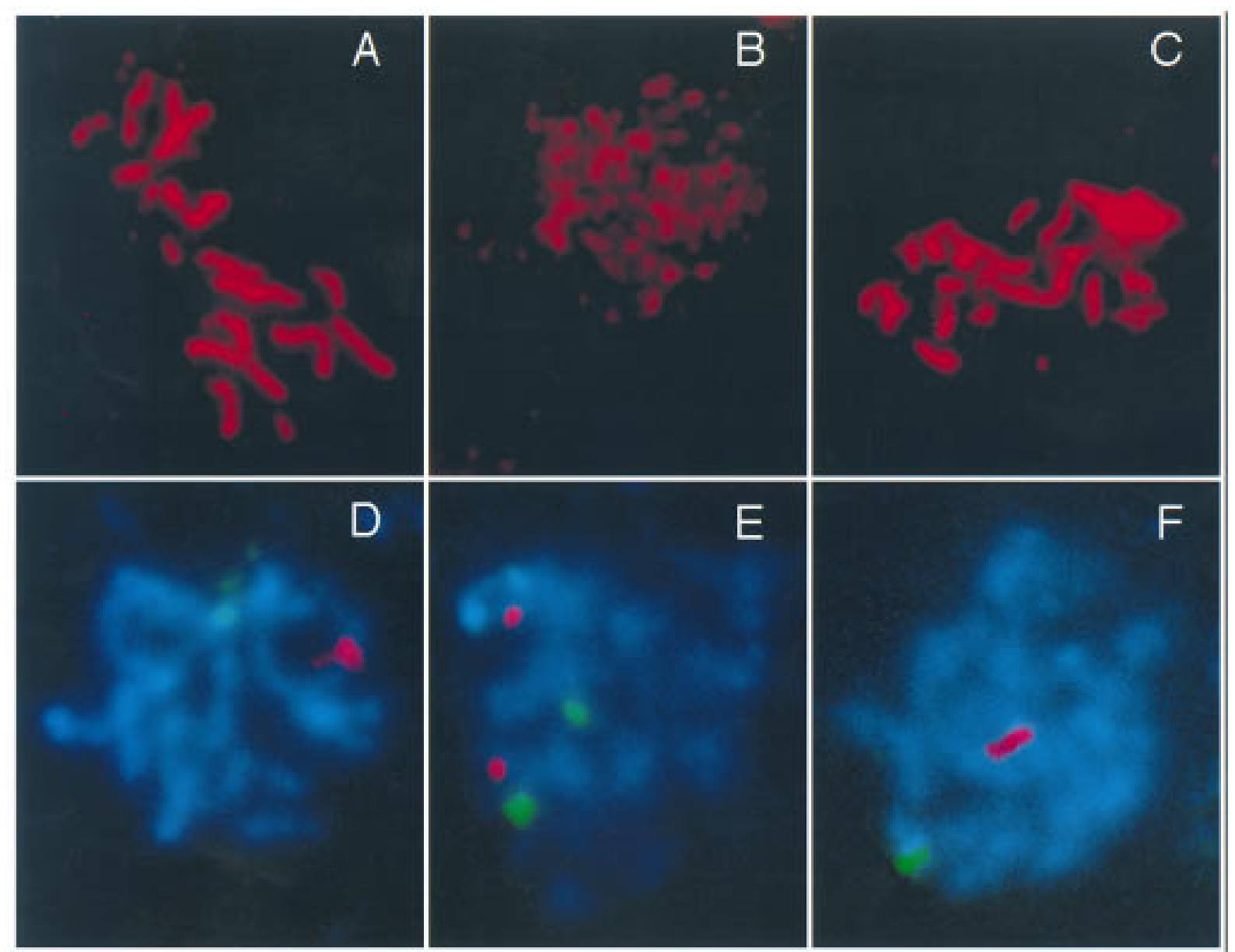

Figure 9. SC formation and homologous pairing are reduced in mrellS. (A-C) N uclei stained with anti-Zipl antibody; (D-F) pai ring status of chromosome I and IV signals (green and red, respectively). Strains are Y 325 (MRE11/mrel1S) and Y 323 (mrel1S/mrel1S). (A) Wild-type pachytene SCs; (B) Zipl-positive mrel1S nucl eus without synapsis; (C) extensive synapsis in mrel1S. The upper right patch corresponds to an overexposed Zipl aggregate. (D) both chromosome I and IV signals are paired in wild type; (E) typical pairing behavior in the mrellS mutant; $(F)$ very rarely both chromosome signals are paired in mrellS.

of homologous DN A pairing. The total amount of SCsin the mutant al lows predictions about the minimum level of DNA pairing if synapsis were homologous. If SC formation exceeds DNA pairing, at least some of the SCS must connect nonhomologous chromosomes.

The approach of combining FISH and immunocytology is complicated by two facts: First, it is at present inapplicable to monitor synapsis by immunocytology and pairing by FISH in the same cell because of the dif- ferent conditions required. Second, not all paired DNA sequences need to be in the context of a SC because pairing precedes SC formation (Scherthan et al. 1992; Weiner and Kleckner 1994). Bel ow, we present statistical evidence that a deficit of homologous pairing relative to the amount of SCs was found, confirming that at least a fraction of the SCs observed by electron microscopy were nonhomol ogous.

Pairing was monitored in a MRE11/mrells and a

Table 4. In mrel1S synapsed nuclei are more frequent than nuclei with both chromosomes I and IV paired

\begin{tabular}{|c|c|c|c|c|c|c|c|}
\hline $\begin{array}{l}\text { Relevant } \\
\text { genotype }\end{array}$ & $\begin{array}{l}\text { Chromosome I } \\
\text { paired (\%) }\end{array}$ & $\begin{array}{c}\text { Chromosome IV } \\
\text { paired }(\%)\end{array}$ & $\begin{array}{l}\text { Both chromosomes I } \\
\text { and IV paired (\%) }\end{array}$ & $\begin{array}{l}\text { Nuclei } \\
\text { counted }\end{array}$ & $\begin{array}{c}\text { (N early) complete } \\
\text { synapsis judged by } \\
\text { Zip1 }(\%)\end{array}$ & $\begin{array}{c}\text { Zipl } \\
\text { positive } \\
(\%)\end{array}$ & $\begin{array}{l}\text { Nuclei } \\
\text { counted }\end{array}$ \\
\hline mrel1S/mrells & 14.7 & 14.9 & 2.9 & 450 & 7.3 & 43.6 & 300 \\
\hline MRE11/mrel1S & 83 & 83 & 72 & 100 & 41 & 60 & 200 \\
\hline
\end{tabular}

Spread nuclei from the same experiment were either hybridized with probes for chromosome I and IV or immunostained with anti-Zipl antibodies. Cells were spread at time points when synapsis was maximal. Zipl-positive nuclei may contain unsynapsed axial el ements and degrading SCs. Only continuous Zipl axes were regarded as synapsed. Fewer nuclei have both chromosomes I and IV signals paired in mrells than expected if synapsis were homologous. 
mrel1S/mrel1S strain at stages corresponding to maximum SC formation, that is, at $5 \mathrm{hr}$ in wild type and at 7 hr in the mutant (see Fig. 8E). Of each same preparation one slide was used for immunostaining with anti-Zip1 antibodies to decorate the SC (Sym et al. 1993) and one was hybridized with a mixture of two differently labeled cosmid probes originating from a small and a large chromosome (chromosomes I and IV) (Fig. 9).

Distances between the homologous signal pairs as well as between nonhomologous signals were determined. DN A sequences connected by a homologous SC are believed to be within $0.7 \mu \mathrm{m}$ (Weiner and Kleckner 1994), and such signals will be referred to as being closely paired. Table 4 lists the percentage of closely paired signals for wild-type and mutant. Each single signal was closely paired in only $\sim 15 \%$ of the cases in the mutant compared to $83 \%$ in the wild type. An even stronger difference is apparent when counting nuclei with both signals paired simultaneously. In only $2.9 \%$ of the mutant, but in $72 \%$ of wild-type nuclei, both signals were paired at once.

Synapsis was quantified by determining the fraction of nuclei with long, bright, continuous Zipl-positive axes (corresponding to class 4 nuclei in Figs. 7 and 8). These could be clearly differentiated from other Zip1-positive nuclei, because the Zipl antibody binds strongly only to the synapsed regions of chromosomes (Sym et al. 1993). In wild type $41 \%$ of the nuclei had extensive SCs, with an average total length of $31.8 \pm 7.0 \mu \mathrm{m}$ (data from 37 nuclei). Only $7.3 \%$ mrel1S nuclei werelargely synapsed, whereas the number of Zipl-positive nuclei was similar to wild type (T able 4). In these nuclei the total length of the SC complement was $28.3 \pm 7.3 \mu \mathrm{m}$ (data from 29 nuclei). Therefore, SC length is not significantly different between wild type and mutant in the subpopulations described (class 4), the average mutant being only $3.5 \mu \mathrm{m}$ or a factor of 0.89 shorter than the average wild-type SC.

If the SCs were homologous in the mrell mutant the $7.3 \%$ of almost completely synapsed nuclei are expected to contribute largely to the fraction of nuclei with both signals paired. Double pairing may al so occur in partially synapsed nuclei (class 2) or by presynaptic alignment in nuclei without synapsis. Therefore, the $7.3 \%$ contribution of the synapsed subpopulation alone represents a minimum estimate for the percentage of nuclei with both signals closely paired. The observed fraction of $2.9 \%$, however, is clearly smaller than predicted by the amount of SC, indicating that a significant portion of the SCs formed in the mrells mutant are connecting nonhomol ogous chromosomes.

\section{Discussion}

rad50 is epistatic to mrel1S

A screen for new genes and functions that become essential after initiation of meiotic DSBs was carried out which lead to the identification of a new al lele of MRE11 with unexpected properties. MRE11 has been described before (Ajimura et al. 1993) as one of the genes required for initiation of meiotic DSBs. The mrell::hisG mutant is epistatic to rad50S, a separation-of-function mutation that is only defective in the processing of the meiotic DSBs, whereas the other function of RAD 50, namely formation of DSBs, is unaffected (Alani et al. 1990; Ogawa et al. 1995). The activity of the mrell allel e described in this work mirrors this property in that it also forms DSBs, but the rad50 null mutation is epistatic to the new allele, which is therefore called mrells. We conclude that the respective proteins that haveal so been shown to interact physically in a two-hybrid assay (Johzuka and Ogawa 1995) are intimately associated with the processes immediately before and after DSB formation.

Sequencing of the mutant allele identified two changes, Pro to Ser at position 84 and Thr to Ile at position 188 of the predicted amino acid sequence. The identified S mutations thus maps to the amino-terminal part of the protein, which shows strong homologies to both eukaryotic homologs of M rell and the prokaryotic SbcD (SbcD has nucl ease activity) (Connelly and Leach 1996), whereas the carboxyl terminus does not exhibit strong sequence conservation. This suggests that the core regions and a possible catal ytic domain resi de in the amino terminal half of the protein and the carboxyl terminus may have a more yeast specific role. Strong homol ogy to the bacterial SbcD is limited to several short blocks throughout the amino terminus. Neither of the two point mutations identified in mrells maps to such a block but to regions conserved among all eukaryotic Mrell relatives. This may mean that these are newly evolved regions in eukaryotes to serve meiosis-specific functions. The affected domain may be involved in regulation of M rellp activity or in conserved protein-protein interactions.

\section{mrel1S causes a defect in DSB processing and repair}

The mrells mutant was analyzed for possible defects during vegetative growth and in meiosis. Resistance to MMS in mrells was between wild-type and homozygous disruptions. No indication for a similar mitotic hyper-recombination as in mrell disruptions was found at two heteroalleles tested. This implies that mitotic functions of the M rel1Sp are largely intact or only weakened and that a possible catalytic function is not seriously impaired. Commitment to meiotic recombination as assayed by return to growth was also intermediate, suggesting that many of the induced DSBs could be repaired on vegetative medium in a mrells strain. However, serious defects were found when cells were required to complete meiosis.

Spore formation and spore viability are strongly reduced in mrel1S and in the mrel1S spol3 mutants. On the other hand, a mrel1S rad50 spol3 triple mutation is viable in meiosis. The most obvious explanation is that MRE11 function is dispensable because rad50 prevents DSB formation. In this study meiotic DSBs were shown to accumulate in the mrel1S/mrel1S mutant; therefore, the defective function is required for processing and repair of DSBs. Quantification of the relative amount of 
broken DNA revealed a difference between rad50S and mrel1S at the his4-LEU 2 locus. After a similar initial increase DSBs accumulated to a higher level in rad50S/ rad50S than in mrel1S/mrells or in mrells/mrellT4. In addition, the latter two leveled off at $7 \mathrm{hr}$ and decreased by $8.5 \mathrm{hr}$, indicating loss of breaks. Although nonspecific degradation of a fraction of DNA ends cannot be ruled out, DN A repair is suggested to explain the loss of breaks because the bands remained sharp at 8.5 hr. Such repair may cause the observed partial recombination competence in a mrel1S strain in the return-togrowth experiment. However, neither heteroduplex DNA nor physical recombinants could be detected at his4-LEU 2 in the homozygous mrel1S strain under conditions where $30 \%$ of wild-type levels would have been detected (data not shown). At the natural hot spot close to THR4 as well as at DED81 (data not shown) differences observed in DSB levels between rad50S and mrel1S were less clear.

It is not known whether Spollp, which remains covalently linked to the $5^{\prime}$ ends of DSBs in rad50S and most likely al so in com1/sae2 mutants (de M assy et al. 1995; Keeney and Kleckner 1995; Liu et al. 1995; Keeney et al. 1997), also does so in mrel1S mutants. It is likely because the DN A ends seem to be blocked from processing. However, a fraction of the DSBs finally disappears, suggesting that the DNA ends have been liberated. The higher instability of DSBs in mrel1S versus rad50S observed at some recombination hot spots may be related to the higher yield of gene conversions in mrel1S versus rad50S observed in return to growth. The fact that in such an experiment a considerable fraction of cells remains viable after induction of meiosis demonstrates that under vegetative conditions in a fraction of the cells every break can be repaired.

The homology of M rellp/Rad50p to the SbcC/SbcD nuclease suggests that $M$ rellp might be the catalytic subunit of a M rellp/Rad50p complex, being di rectly responsible for $5^{\prime}$ resection at DSB sites either exo- or endonucleolytically. This is compatible with the results from physical DSB analysis and recombination studies assuming that a different pathway that works more efficiently during mitosis (as seen in return to growth) finally processes the breaks. Taking into account that mitotic functions are largely intact, as discussed above, we propose that a domain that regulates meiosis-specific $M$ rellp activity is mutated in M rel1Sp. Recent results from studies in vegetatively growing cells relate $\mathrm{M}$ rell, Rad50, and Xrs2 to exonucl eolytic function. Ivanov et al . (1996) have studied $\mathrm{HO}$-induced illegi timate recombination and found a retardation of $5^{\prime}$ resection in rad50 and xrs2 mutants. In mrell strains, repair thought to involve $5^{\prime}$ resection is 10 -fold reduced at $\mathrm{HO}$ cuts (Moore and Haber 1996) and 5' degradation is even slower in mrell than in rad50, but not absent (J. Haber, pers. comm.). These experiments show that there is residual $5^{\prime} \rightarrow 3^{\prime}$ resection in the absence of MRE11. One important difference between vegetative and meiotic repair processes requiring $\mathrm{Mrellp}$ is the presumptive protection of $5^{\prime}$ ends by Spol1p in mei osis (Keeney et al . 1997). A role for
M rel1p/Rad50p could therefore be to liberate Spollp by a single strand endonucleolytic step. A compati ble activity has also been demonstrated for SbcC/SbcD. In any case, M rellp should be associated with mei otic chromosomes. When DSB processing was blocked in a rad50S mutant Myc-tagged M rellp was found clustered in distinct foci of varying intensity within spread nuclei (Nairz 1997).

Intragenic complementation between mrel1S and 3' disrupted alleles of MRE11

The fact that intragenic complementation was observed between mrel1S and the 3 ' disruptions strongly suggests that DSB initiation and DSB processing functions reside in separate domains.

The regions truncated in the complementing alleles mrel1-T4 and mrel1-T10 lack strong sequence conservation. They are nevertheless essential for DSB initiation, probably for interaction with yeast-specific factors that allow access to the DNA or that activate Spol1 endonuclease. These interactions as well as binding to Rad50p, which has been shown to involve the amino terminus (Johzuka and Ogawa 1995), are intact in the mrel1S mutant. The intragenic complementation is best explained by homotypic interaction of $\mathrm{M}$ rell proteins. This is in good agreement with the demonstration that M rellp interacts with itself in two-hybrid studies (Johzuka and Ogawa 1995). Intragenic complementation for mrell alleles can thus be explained by a model in which a partially functional heteromultimeric complex contains both Mrel1-T4(T 10)p and Mrel1Sp. Whereas Mrel1Sp allows Spollp to interact with the DNA, M rel1-T4(T 10)p may contribute the 5 ' resecting activity either alone or in conjunction with another component. Less likely the carboxy-terminally truncated alleles reactivate the processing function of $\mathrm{M}$ rel1Sp through direct interaction or $\mathrm{M}$ rel1Sp and $\mathrm{M}$ rel1-T $4 \mathrm{p}$ work independently and sequentially.

With MRE11 and RAD50 two genes are known to be required both for initiation and repair of DSBs and these functions can be separated in both genes. Furthermore, their products interact with each other physically. Therefore, we propose a model in which a complex, a "recombinosome", consisting of Rad50p, M rellp, and other components required for recombinational repair, must be present at a given hot spot to allow Spollp to cut. The use of such bifunctional complexes would greatly enhance repair efficiency by eliminating the damage recognition step. Others have presented indirect evidence that even the homologous template for DNA repair may al ready be in place at the time of DSB initiation (Rocco and N icolas 1996; Xu and Kleckner 1995).

mrel1S causes reduced, nonhomologous synapsis and decreases spore viability

The failure to process and repair the DSBs leads to a number of observable consequences. Spore formation is generally reduced in mrel1S/mrel1S, and the number of 
dyads rises considerably at the cost of the number of complete tetrads. Of those spores formed, viability is extremely low (1\%). The first meiotic division is delayed considerably in the SK 1 strain background but not in the disruption mutants (Fig. 8A-D). The delay was al so observed for rad50S (Alani et al. 1990) and for com1/sae2 (Mc Kee and Kleckner 1997; Prinz et al. 1997). In other backgrounds these mutations may cause a complete block. In the case of dmcl the block has been shown to monitor DSBs, utilizing the checkpoint genes MEC1, RAD17, and RAD24 (Lydall et al. 1996).

The spreading of yeast nuclei revealed other consequences of the absent repair of DSBs. SC precursors were enriched relative to wild type, and a new class of nuclei containing long unsynapsed AEs appeared possibly as a consequence of delayed synapsis, most likely caused by the absence of $3^{\prime}$ single-stranded ends for homology search. However, even in the absence of repair of the majority of DSBs there was extensive SC formation in a fraction of mrel1S nuclei. Such synapsis has also been observed in rad50S cells (Loidl et al. 1994) and in com1/ sae2 nuclei (Prinz et al. 1997). However, in all such cases, synapsis seemed aberrant in that sometimes network-like structures were observed but never the complete chromosome complement with 16 separate bivalents. In this study evidence for partner switches of axial elements is presented, which suggests nonhomologous synapsis. In corroboration of this finding the fraction of nuclei with homologously associated FISH signals was compared to the fraction of nuclei exhibiting extensive SCs. Considerably more nuclei were found with almost the complete chromosome complement synapsed than nuclei with two signals paired concomitantly. We conclude that at least in a fraction of the completely synapsed nuclei homologous signal s were not paired, that is, that at least some synapsed regions were nonhomologous. It has been shown earlier for yeast that synapsis of nonhomologous chromosomes is possible in haploid yeast (Loidl et al. 1991). Also nonhomologous synapsis in haploids depends on RAD50 and other DSB initiation genes (F. Klein, unpubl.). We therefore propose that synapsis requires the presence of DSBs but that homologous synapsis is only ensured by at least the formation of the 3 '-overhanging single-stranded DN A ends. In DSB negative mutants (e.g., in mrell-T4/mrel1-T4) synapsis does normally not take place, but in DSB-accumulating mutants the homologous registration fails while synapsis occurs by default and irrespective of homologies. The few cases where long axial elements and extensive synapsis is found in mrel1-T4/mrel1-T4 may be explained by initiation of synapsis through DSBs bel ow the limits of physical detection. These DSBs may only occur in a very small subpopulation and may not be sufficient to ensure viability.

A model presenting a unified view of the relation between DNA metabolism and formation of SC $s$ and their precursors is introduced (Fig. 10). Axial el ements do form in the absence of DSBs, as observed in many different null mutants. Unprocessed DSBs allow for synapsis which is at least partially nonhomologous, as shown for
DNA metabolism

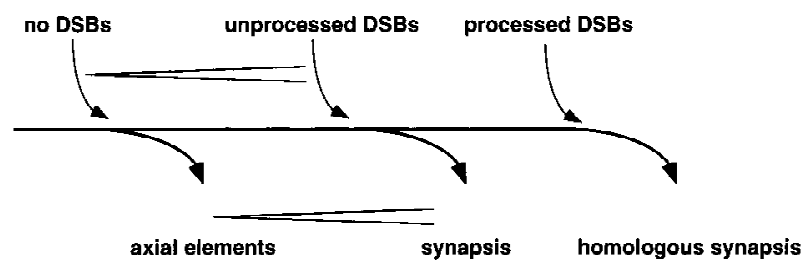

$\mathrm{SC}$ related morphology

Figure 10. Model of the relation between DSBs and synapsis. It is proposed that unprocessed DSBs are sufficient to allow for synapsis. Only when DSBs are repaired successfully is homologous synapsis possible. Rare synapsis observed in the mrel1-T4 homozygote, where neither induction of meiotic recombination nor DSBs were detected, could be explained if DSBs below the limit of detection were able to induce SC formation. $(\Varangle$ Increasing amount of either SCs or DSBs.

mrel1S. Synapsis induced by unrepaired DSBs may represent a default pathway that comes into effect when no homologies are found representing the uncoupling of synapsis from homol ogy search. Homol ogous synapsis is ensured only by the recombination processes that follow DSB formation, processing, and strand invasion. These processes are likely to establ ish homologous interactions that allows synapsis of the proper axial elements.

\section{Materials and Methods}

Media, genetic techniques, growth regimen, and ether killing

Yeast was grown in rich medium (YPD), synthetic complete medium lacking factors (SC - ) or minimal medium supplemented with specific factors (SD+) as described (Rose et al. 1990). Presporulation medium (YPA) was $1 \%$ yeast extract (Difco), 2\% peptone (Difco), 2\% potassium acetate, and SPM was $2 \%$ potassium acetate ( $\mathrm{pH} 7$ ) (optionally solidified with $2 \%$ agar). However, sporulation of strain $\mathrm{Y} 136$ on solid medium was performed on $\mathrm{SPM}^{+}(0.25 \%$ yeast extract, $0.1 \%$ glucose, $1.5 \%$ potassium acetate plus one-fortieth volume of an amino acid and nucleotide mix containing $40 \mathrm{mg}$ of Pro, $80 \mathrm{mg}$ of Tyr, 200 mg of His, Leu, Lys, Met,Trp, and Arg, $400 \mathrm{mg}$ of Ade and U ra, and 1 gram of Phe per $25 \mathrm{ml}$ ). MMS (Schuchardt) was added to YPD just prior to pouring plates. Asci were digested with 200 $\mu \mathrm{g} / \mathrm{ml}$ of Zymolyase 20T (Seikagaku Kogyo Ltd) for $20 \mathrm{~min}$ at $37^{\circ} \mathrm{C}$ for tetrad dissection.

Sporulation for DSB assays, SC spreading, and return to growth was done as described by Loidl et al. (1994). Commitment to meiotic recombination was monitored in return-togrowth experiments as described (Sherman and Roman 1963; Alani et al. 1990). Samples of synchronized sporulating cells were taken at the specified time after transfer to liquid SPM, sonicated, diluted, and plated on at least two Y PD, SC - HIS, and SC-ARG petri dishes. Ether treatment for enrichment of spores by selectively killing unsporulated cells was performed as described recently (Prinz et al. 1997). 


\section{Plasmids}

p3 was derived from pN KY 1070 (a YCP50-based RAD50 plasmid from N. Kleckner, Harvard U niversity, Cambridge, MA) by cutting with Sall and religating it to yield p1. p1 was digested with EcoRI and ligated to a 3.95-kb EcoRI fragment from R990 (S. Roeder, Yale University, N ew Haven, CT) containing ADE2 (and $460 \mathrm{bp}$ of mer2 sequence). U RA 3 was removed by del eting a $1.6 \mathrm{~kb}$ Smal-N rul fragment. p21 was constructed by ligating a 2.2-kb BamHI-Nrul fragment from pTW15 (R. Esposito, University of Chicago, IL) containing SPO 13 coding sequence into pRS315 (Sikorski and Hieter 1989), which was cut with HindlII, blunted by filling in, and then cut with BamHI. p265 originated from YCplac33 (Gietz and Sugino1988) into which a 4.3-kb BamHI fragment containing MRE11 was inserted. p266 is derived from p265 by gap repair (see Cloning and Sequencing, below).

\section{Mutagenesis}

Strain Y 136 was grown on SC-ADE-URA for 2 days, transferred to YPD for $8 \mathrm{hr}$, and sporulated on $2 \%$ potassium acetate plates for $24 \mathrm{hr}$. Asci were resuspended in $150 \mu \mathrm{l}$ of $10 \mathrm{~mm}$ DTT with $50 \mu \mathrm{g}$ of Zymolyase 20T (Seikagaku), incubated for $90 \mathrm{~min}$ at $37^{\circ} \mathrm{C}$, and sonicated for $5 \times 5 \mathrm{sec}$ on ice to obtain single spores. Spores $\left(5 \times 10^{7}\right)$ in $1 \mathrm{ml}$ were mutagenized for $30 \mathrm{~min}$ at $30^{\circ} \mathrm{C}$ with 27 or $32 \mathrm{ng} / \mathrm{ml}$ of MNNG (Sigma) to a viability of $86 \%$ or $36 \%$ (corresponding to a 5 - or 20 -fold increase in canavanineresistant colonies as a measure of mutational yield) and frozen in $50 \%$ glycerol at $-80^{\circ} \mathrm{C}$. After determination of viability the mutagenized spores were diluted and plated to a density of 180 or 275 colonies per SC-ADE plate. After 2 days colonies were replica-plated to $\mathrm{SPM}^{+}$. After 3 days of sporulation at $30^{\circ}$ the colonies were stamped onto YPD, ether treated to select for spores, and incubated for another 3 days at $30^{\circ} \mathrm{C}$. Twenty-two candidates of 18,000 colonies of the first mutagenesis and 16 candidates of 13,000 col onies of the second mutagenesis formed red patches and were isolated.

\section{Cloning and sequencing}

Because difficulties were expected in crossing out mutant alleles that prevent successful meiosis from a homothallic diploid strain, the affected gene was cloned by direct complementation of the spore viability defect. Among eight mutant candidates, number 220 was chosen for complementation. The candidate was transformed with a CEN -based genomic U RA3 library [a gift of Brian Jensen and Breck Byers (University of Washington, Seattle) made from a A 364A derivative], and transformants were selected on SM -URA, SM -ADE, and SM - LEU to ascertain the presence of both the library plasmid and of plasmids p21 (SPO 13, LEU 2) and p3 (RAD50, ADE2), which allows initiation of recombination in cells with "white" progeny. The resulting colonies were sporulated on SPM ${ }^{+}$, replica plated to YPD, ether treated, and examined for the appearance of white patches. One such patch was detected, indicating that cells had regained the ability to form viable spores in the presence of RAD50 and SPO 13. Such spores were directly mated to strain $Y 7$, and a descendant (ho, RAD50, spo-) was further crossed to strain $Y 5$. In 12 of 12 complete tetrads from this cross, the sporulation defect segregated $2: 2$, indicating Mendelian behavior of a recessive gene. When 104 spores from this cross were analyzed, 51 were $\mathrm{spo}^{-}$and 53 were $\mathrm{SPO}^{+}$.

The complementing plasmid was isolated, the large insert was subcloned into YCplac33, and the resulting plasmid p265, containing a 4.3-kb BamHI fragment of the insert with a central
Clal site, proved sufficient to complement the sporulation defect of Y 233. N either the internal 2.0-kb Clal-BamHI nor the $2.3-\mathrm{kb}$ Clal-BamHI fragment alone could complement identifying the Clal site as mapping within the coding sequence. Both fragments were subcloned into Bluescript SK- and sequenced from the Clal site by the dideoxy chain-termination method (Sanger et al. 1977) using the T7 sequencing kit (Pharmacia) and ${ }^{35}$ S-labeled dATP ( $\mathrm{N}$ ew England N uclear). The result identified the sequence as a meiotic recombination gene, MRE11, that had just been published by Johzuka and Ogawa (1995).

\section{The cloning and sequencing of mrells}

mrel1S was recovered by gap repair (Orr-Weaver et al. 1983): A haploid strain (Y227 mrel1S, ura3) was transformed to URA ${ }^{+}$ with the gel-purified 7.9-kb AflII-N rul fragment of p265 devoid of the complete MRE11 coding and of 170-bp MRE11 upstream sequence (Fig. 3A ). The gap-paired plasmid, p266, was recovered from a transformant, amplified in E. coli, and transformed into Y 233 (mrel1S/mrel1S) for complementation of the mrel1S-dependent sporulation defect. p266 did not restore sporulation in nine of nine transformants tested.

For sequencing of mrel1S (p266) and MRE11 (p265) various restriction fragments were subcloned into Bluescript (SK - ). In addition, a set of exonuclease III-generated deletions were derived from Sphl-Aflll double-digested p266 (Sambrook et al. 1989) and sequenced using universal primers MJ3 and MJ4 (MJ3, 5'-AGCGGATAACAATTTCACACAGGA-3', MJ4, 5'-CGCCAGGGTTTTCCCAGTCACGAC-3'). The SK1-derived mrellS sequence differed from the published sequence (Johzuka and Ogawa 1995) at two positions in the promotor ( -28 and -4$), 4$ redundant sites $(+219,+786,+843,+1155)$, one site close to the stop codon leading to a frame shift $(+1928)$, which renders the protein 49 amino acids longer [previously mentioned by J. Skelton and C.M. Churcher (unpubl.), GenBank accession no. S57592], one nonconservative change in this tail (+1975), as well as three nonconservative changes in the $3^{\prime}$ part of the gene $(+250,+563,+1138)$. To clarify which of the base differences was responsible for the mrel1S phenotype, MRE11 from p265 was sequenced as well. MRE11 on p265 and mrel1S on p266 differ at one redundant and two nonconservative sites, namely at positions +250 and +563 . In addition, wild-type MRE11 was recovered from SK 1 by gap repair and sequenced as well. It proved identical to the MRE11 sequence of p265 for both position +250 and +563 . The SK1-derived sequence has been submitted to GenBank (accession no. U60829).

\section{Transposon mutagenesis and complementation analysis}

A 2.0-kb BamHI-Clal fragment containing the 5' part of MRE11 and a $2.3-\mathrm{kb}$ Clal-BamHI fragment harboring the $3^{\prime}$ part were cloned into pHSS6 separately and subjected to in vivo transposon mutagenesis in E. coli using mTn3(LEU 2, lacZ without promotor, and ATG) as described (Seifert et al. 1986). Orientation and location of inserted transposons was determined by restriction analysis, taking advantage of a BamHI site at the $5^{\prime}$ end of IacZ on the end of the 6.6-kb transposon. Appropriate clones were digested with Notl and used to construct MRE11 disruptions in strain N KY 857 by single-step gene replacement (Rothstein 1983) selecting for LEU prototrophs. Yeast transformation was done according to Gietz et al. (1992). Correct integration of disrupted DNA fragments was confirmed both by complementation analysis with a mrel1S strain (Y 224) and by Southern blotting probing with a mixture of the $2.0-\mathrm{kb}$ and $2.3-$ kb BamHI-Clal fragments (not shown).

The transposon in mrel1-T20 mapped within $50 \mathrm{bp}$ of the 
start codon of MRE1l and the lacZ ORF is oriented opposite to the MRE11 ORF (Fig. 3A). In mrel1-T4 and mrel1-T10, IacZ is fused in-frame to the remaining mrell fragment: Patches of sporulated and unsporulated mrel1S/mrell-T4 and mrellS/ mrel1-T10 heterozygotes were transferred to nitrocellul ose filters (Schleicher \& Schuell) from YPD and sporulation plates, respectively, frozen at $-80^{\circ} \mathrm{C}$ for $30 \mathrm{~min}$ and thawed to break up the cells. Ten microliters of X-gal solution $(2 \mathrm{mg} / \mathrm{ml}$ in dimethylformamide) was added to the cells, which turned blue in sporulated, but not in unsporulated, patches, indicating expression of $\beta$-galactosidase activity from the MRE11 promoter. mrel1-T40 and mrel1-T16, which are disrupted at roughly the same positions as mrel1-T4 and mrel1-T10, respectively, by equally oriented transposons do not show meiotically induced lacZ activity, suggesting that integration was out of frame.

\section{DSB}

Meiotic DNA DSBs were monitored at three hot spots, one close to THR4 (Goldway et al. 1993), one at DED 81 (de M assy and $\mathrm{N}$ icolas 1993), and one at the artificial his4-LEU 2 construct
(Cao et al. 1990; Storlazzi et al. 1995) Physical maps of the hot spots are given there. Yeast DN A was isolated as described by Cao et al . (1990) and modified by Bishop et al . (1992), except that the ether extraction after phenol/chloroform/isoamyl alcohol (25:24:1) was replaced by a chloroform/isoamyl alcohol (24:1) extraction. DNA was taken at the time indicated, digested appropriately, separated on $0.8 \%$ TAE-buffered agarose gels, and transferred to Hybond-N nylon membranes (Amersham) by alkaline blotting. Probes were gel purified by Elu-Quick (Schleicher \& Schuell) according to the manufacturer's protocol and radioactively labeled by random priming using $\left[\alpha^{-32} P\right]-d A T P$ (NEN).

A $0.89-k b$ HindlII fragment from pMJ338 (M. Lichten, National Cancer Institute, Bethesda, MD) mapping close to the THR4 hotspot was used to probe Bglll-digested genomic DNA. For examination of the artificial his4-LEU 2 hot spot, DN A was digested with Pstl and probed with a combination of a $0.7-\mathrm{kb}$ and a 0.9-kb Pstl-EcoRI fragment from pN KY 155 (probe B) or a 1.8-kb Pstl-EcoRI fragment from pN KY 291 (probe A) (Storlazzi et al. 1995; Xu and Kleckner 1995). To probe for the hot spot close to DED81, an EcoRV-Bglll fragment of the ARG4 gene was used (de Massy and Nicolas 1993).

Table 5. Strains used in this study

\begin{tabular}{|c|c|}
\hline Strain (SK1) & Genotype (MATa/MAT $\alpha, \mathrm{HO}$ ) \\
\hline NKY 857 & MATa, ho::LYS2, lys2, leu2::hisG, his4X, ura3 \\
\hline Y5 & MAT $\alpha$, ho::LYS2, lys2, leu2::hisG, his4B, ura3, ade2::hisG::URA3::hisG \\
\hline Y7 & MATa, ho::LYS2, ade2::hisG, ura3 \\
\hline Y 136 & MATa/MAT $\alpha$, HO, rad50::hisG, leu2::hisG, his4B, ade2::hisG, ura3, pTW15 (SPO 13, U RA3), p3 (RAD50, ADE2) \\
\hline Y 224 & MAT $\alpha$, ho::LYS2, ura3, ade2::hisG, leu2::hisG, mrel1S \\
\hline Y227 & MAT $\alpha$, ho::LYS2, ura3, ade2::hisG, mrel1S \\
\hline Y233 & MATa/MAT $\alpha$, HIS4/his4B, ura3/ura3, ADE2/ade2::hisG, LEU 2/leu2::hisG, SPO13/spo13::hisG, mrel1S/mrel1S \\
\hline Y 253 & MATa, ho::LYS2, Iys2, leu2::hisG, his4X, ura3, mrel1-T20(-LEU 2) \\
\hline Y254 & MATa, ho::LYS2, Iys2, leu2::hisG, his4X, ura3, mrel1-T37(-LEU 2) \\
\hline Y255 & MATa, ho::LYS2, Iys2, leu2::hisG, his4X, ura3, mrel1-T24(-LEU2) \\
\hline Y256 & MATa, ho::LYS2, Iys2, leu2::hisG, his4X, ura3, mrel1-T34(-LEU 2) \\
\hline Y257 & MATa, ho::LYS2, Iys2, leu2::hisG, his4X, ura3, mrell-T4(-LEU 2) \\
\hline Y 258 & MATa, ho::LYS2, Iys2, leu2::hisG, his4X, ura3, mrel1-T40(-LEU2) \\
\hline Y261 & MATa, ho::LYS2, Iys2, leu2::hisG, his4X, ura3, mrel1-T16(-LEU 2) \\
\hline Y262 & MATa, ho::LYS2, Iys2, leu2::hisG, his4X, ura3, mrel1-T10(-LEU 2) \\
\hline Y $292 \times 294$ & $\begin{array}{l}\text { MATa/MAT } \alpha \text {, ho::LYS2/ho::LYS2, rad50S-KI81::U RA3/rad50S-KI81::URA3, ura3/ura3, LEU 2/leu2R, } \\
\text { arg4 } \Delta 10 / \text { arg4 } 10 \text {, ADE2/ade2::hisG, mrel1S/mrel1S }\end{array}$ \\
\hline Y 323 & $\begin{array}{l}\text { MATa/MAT } \alpha \text {, ho::LYS2/ho::LYS2, his4B-LEU 2-Mlul/his4X-LEU 2-Mlul::BamHI-U RA3, leu2::hisG/leu2::hisG, } \\
\text { ura3/ura3, ADE2/ade2::hisG, arg4-Bgl/arg4-Nsp, mrel1S/mre11S }\end{array}$ \\
\hline Y 324 & $\begin{array}{l}\text { MATa/MAT } \alpha \text {, ho::LYS2/ho::LYS2, his4B-LEU 2-Mlul/his4X-LEU 2-Mlul::BamHI-U RA3, leu2::hisG/leu2::hisG, } \\
\text { ura3/ura3, ADE2/ade2::hisG, arg4-Bgl/arg4-Nsp, mre11S/mrel1-T4(-LEU 2) }\end{array}$ \\
\hline Y 325 & $\begin{array}{l}\text { MATa/MAT } \alpha \text {, ho::LYS2/ho::LYS2, his4B-LEU 2-Mlul/his4X-LEU 2-Mlul::BamHI-U RA3, leu2::hisG/leu2::hisG, } \\
\text { ura3/ura3, ADE2/ade2::hisG, arg4-Bgl/arg4-N sp, mrel1S/MRE11 }\end{array}$ \\
\hline Y 327 & $\begin{array}{l}\text { MATa/MAT } \alpha \text {, ho::LYS2/ho::LYS2, his4B-LEU 2-Mlul/his4X-LEU 2-Mlul::BamHI-U RA3, leu2::hisG/leu2::hisG, } \\
\text { ura3/ura3, ADE2/ade2::hisG, arg4-Bgl/arg4-N sp, mrel1-T4-(LEU 2)/mrel1-T4-(LEU 2) }\end{array}$ \\
\hline Y 328 & $\begin{array}{l}\text { MATa/MAT } \alpha \text {, ho::LYS2/ho::LYS2, his4B-LEU 2-Mlul/his4X-LEU 2-Mlul::BamHI-U RA3, leu2::hisG/leu2::hisG, } \\
\text { ura3/ura3, ADE2/ade2::hisG, arg4-Bgl/arg4-N sp, mrel1-T20-(LEU 2)/mrel1-T20-(LEU 2) }\end{array}$ \\
\hline Y 329 & $\begin{array}{l}\text { MATa/MAT } \alpha \text {, ho::LYS2/ho::LYS2, lys2/lys2, his4B-LEU 2-Mlul/his4X-LEU 2-Mlul::BamHI-U RA3, leu2::hisG/ } \\
\text { leu2::hisG, ura3/ura3, ADE2/ade2::hisG, arg4-Bgl/arg4-Nsp, rad50S::U RA3/rad50S::U RA3 }\end{array}$ \\
\hline Y 401 & $\begin{array}{l}\text { MATa/MAT } \alpha \text {, ho::LYS2/ho::LYS2, rad50::hisG::U RA 3::hisG/rad50::hisG::U RA3::hisG, ura3/ura3, LEU 2/leu2::hisG, } \\
\text { ADE2/ade2::hisG, HIS4/his4B, spo13::hisG/spo13::hisG }\end{array}$ \\
\hline Y 402 & $\begin{array}{l}\text { MATa/MAT } \alpha \text {, ho::LYS2/ho::LYS2, rad50::hisG::U RA3::hisG/rad50::hisG::U RA3::hisG, ura3/ura3, LEU 2/leu2::hisG, } \\
\text { ADE2/ade2::hisG, HIS4/his4B, spo13::hisG/spo13::hisG, mre11S/mrel1S }\end{array}$ \\
\hline Y 403 & $\begin{array}{l}\text { MATa/MAT } \alpha \text {, ho::LYS2/ho::LYS2, ADE2/ade2::hisG, ura3/ura3, LEU 2/leu2::hisG, HIS4/his4B, spo13::hisG/ } \\
\text { spo13::hisG, mrel1S/mre11S }\end{array}$ \\
\hline Y 442 & MAT $\alpha$, ho::LYS2, leu2::hisG, ade2::hisG, ura3, mrel1-T10(-LEU 2) \\
\hline Y9D $\times 2 A$ & $\begin{array}{l}\text { MATa/MAT } \alpha \text {, ho::LYS2/ho::LYS2, ura3/ura3, LEU 2/leu2::hisG, ADE2/ade2::hisG, HIS4/his4B, spo13::hisG/ } \\
\text { spo13::hisG }\end{array}$ \\
\hline
\end{tabular}


Quantification of radioactive label was done on a PhosphorImager (Storm 840 from M olecular Dynamics). For each Iane, a two-dimensional intensity profile was generated and peaks corresponding to parental and DSB bands were integrated after re moving background noise. Signal intensity was calculated as a ratio of DSB value versus parental value.

Spreading, immunocytology, FISH, and silver staining for el ectron microscopy

All cytological techniques used are described in detail elsewhere (Engebrecht et al. 1997). Spreads were prepared as described originally (Loidl et al. 1991). In brief, $10 \mathrm{ml}$ of sporulation culture was centrifuged and resuspended in $1 \mathrm{ml}$ of spheroplasting solution ( $2 \%$ potassium acetate, $0.8 \mathrm{M}$ sorbitol, 10 mM DTT), including $7 \mu \mathrm{l}$ of Zymolyase $20 \mathrm{~T}(10 \mathrm{mg} / \mathrm{ml})$, and digested at $37^{\circ} \mathrm{C}$ until cells lysed in $1 \%$ sodium Sarkosyl. The reaction was stopped by adding $10 \mathrm{ml}$ of ice-cold solution II [0.1 м 2-(N-morpholino) ethane sulfonic acid, $1 \mathrm{~m}$ sorbitol, $1 \mathrm{~mm}$ EDTA, $0.5 \mathrm{mM} \mathrm{M} \mathrm{gCl}_{2}$ ], and the spheroplasts were spun down at low speed and resuspended in $1 \mathrm{ml}$ of solution II. On a clean slide $20 \mu \mathrm{l}$ of cell suspension was prefixed with $40 \mu$ of fixative (4\% paraformal dehyde, $3.4 \%$ sucrose), lysed with $80 \mu \mathrm{l}$ of $1 \%$ lipsol, and fixed with $80 \mu$ l of fixative.

For silver staining slides were dryed overnight, washed with water, and air-dried. Slides were incubated in a humid chamber with $100 \mu \mathrm{l}$ of a silver nitrate solution ( 5 grams plus $5 \mathrm{ml}$ of $\mathrm{H}_{2} \mathrm{O}$ ) under a nylon mesh at $60^{\circ} \mathrm{C}$ for $40 \mathrm{~min}$. For electron microscopy silver-stained spreads were transferred on a plastic film (from 1\% Formvar in chloroform) to microscopical grids and examined in a Zeiss EM 900 at $50 \mathrm{kV}$ and 3000- or 7000-fold magnification. For immunostaining, drying of the preparations was prevented during all of the procedure. Slides were washed with PBS (10×PBS: 75.97 grams of $\mathrm{NaCl}, 9.94$ grams $\mathrm{N} \mathrm{a}_{2} \mathrm{HPO}_{4}$, 4.14 grams of $\mathrm{N} \mathrm{aH}_{2} \mathrm{PO}_{4} / 1$ liter of $\mathrm{H}_{2} \mathrm{O}$ ), blocked for 10 min with $100 \mu \mathrm{l}$ of blocking buffer ( $0.5 \% \mathrm{BSA}$ and $0.2 \%$ gelatin in $1 \times \mathrm{PBS})$ under a coverslip, and incubated with $40 \mu$ of a 1:100 dilution of mouse anti-Zipl antibody (in blocking buffer) at $4^{\circ} \mathrm{C}$ in a humid chamber overnight. After washing in PBS the slide was incubated with $40 \mu \mathrm{l}$ of FITC-conjugated goat anti-rabbit secondary antibody (Sigma) for $2 \mathrm{hr}$ at room temperature, washed again in PBS, and mounted in antifade buffer (Vectashield) with DAPI $(0.4 \mu \mathrm{g} / \mathrm{ml})$.

For FISH we followed a variation of the protocol of Scherthan et al. (1992) described in Engebrecht et al. (1997). A mixture of Cy3-labeled cosmid ATCC 70929 (34-kb insert from the right arm of chromosome IV) and biotin-label ed cosmid ATCC 70893 (33-kb insert from the left arm of chromosome I) was used to hybridize the respective loci in the spread nuclei. ExtravidinFITC [Sigma 1:200 in blocking solution (3\% bovine serum albumin (BSA)/4×SSC/0.1\% Tween 20)], biotin (Sigma, 1:200 in blocking solution), and again extravidin-FITC (1:200) were applied in consecutive rounds to create the signal for the biotinlabeled probe. DNA was stained for $5 \mathrm{~min}$ with DAPI-containing buffer $[40 \mathrm{ml}$ of Mcllvaine $(9 \mathrm{~mm}$ citric acid, $80 \mathrm{~mm}$ $\mathrm{N} \mathrm{aH}_{2} \mathrm{PO}_{4}, 2.5 \mathrm{~mm} \mathrm{M} \mathrm{gCl}$ ), $5 \mathrm{ml}$ of 10×PBS, $5 \mathrm{ml} 40 \%$ paraformaldehyde (pH 7.5), $250 \mu \mathrm{l}$ of DAPI $(0.2 \mathrm{mg} / \mathrm{ml})]$. Samples were first dehydrated for 2 min in 70\% EtOH, 2 min in 96\% EtOH, and then mounted in antifade buffer.

Fluorescent microscopical examination was performed on a Zeiss Axioplan; pictures were digitalized by a Photometrics CCD camera and processed by IPlab software.

\section{Sequence analysis}

Sequence analysis was done via internet on the BCM search launcher (http://kiwi.imgen.bcm.tmc.edu:8088/search-launcher/ launcher.html) using BLAST and BEAUTY programs for sequence comparison (Altschul et al. 1990; Smith et al. 1996). Coiled-coils were predicted according to Lupas et al. (1991) via BCM using window sizes 21 and 14, and sequence motives were found with PROSITE (Bairoch et al. 1995; http://expasy. hcuge.ch/sprot/ prosite.html).

\section{Strains}

All strains are isogenic derivatives of SK1 (Kane and Roth 1974) and are listed in Table 5. For intragenic complementation analysis, isogenic diploid strains were derived from the MAT $\alpha$ parent Y224 (mrel1S) and the following MATa strains: Y 253 (mrellT20), Y 254 (mrel1-T37), Y 255 (mrel1-T24), Y 256 (mrel1-T34), Y 257 (mrel1-T4), Y 258 (mrel1-T40), Y 261 (mrel1-T16), Y 262 (mrel1-T10), and N KY 857 (MRE11). For DSB assays, cytological analysis, test of MMS resistance, and return-to-growth experiments, the following strains were used: Y 325 (MRE11/mrel1S), Y327 (mrell-T4/mrell-T4), Y328 (mrell-T20/mrel1-T20), Y329 (rad50S/rad50S), Y323 (mrells/mrells), and Y324 (mrel1S/mrell-T4). They are descendants of strains N KY 1303 and NKY 1543 described in Storlazzi et al. (1995) and Xu and Kleckner (1995) carrying arg4 heteroalleles (arg4-Bgl or arg4$\mathrm{Nsp}$ ) and his4 heteroalleles (his4X-LEU2-Mlul::BamHI or his4B-LEU 2-Mlul).

\section{Acknowledgments}

Many thanks go to Rochelle E. Esposito, Shirleen Roeder, Mike Lichten, and especially Liuzhong $\mathrm{Xu}$ and $\mathrm{N}$ ancy Kleckner for sharing plasmids and strains. We are indebted to Brian Jensen and Breck Byers for providing the library, to Quan-wen Jin for his expert advice in "fishing" and for providing probes, to Rainer de $M$ artin for printing the col or figure and hel $p$ in sequencing, to Peter M oens for sending us anti-Zipl antibody, and to Susanne Prinz for close cooperation. The ideas in this work were born during the stimulating time we spent in the laboratory of Breck Byers. We are grateful to Jim Haber, Hideyuki Ogawa, and Dieter Schweizer for critical comments on the manuscript. This work was supported by grants S5815-BIO and in part S5807-BIO of the Austrian Science Foundation (FWF) and Jubiläumsfondsprojekt nr. 5955 of the Österrei chische $\mathrm{N}$ ational bank.

The publication costs of this article were defrayed in part by payment of page charges. This article must therefore be hereby marked "advertisement" in accordance with 18 USC section 1734 solely to indicate this fact.

\section{References}

Ajimura, M., S.H. Leem, and H. Ogawa. 1993. Identification of new genes required for meiotic recombination in Saccharomyces cerevisiae. Genetics 133: 51-66.

Alani, E., R. Padmore, and N. Kleckner.1990. Analysis of wildtype and rad50 mutants of yeast suggests an intimate relationship between meiotic chromosome synapsis and recombination. Cell 61: 419-436.

Altshul, S.F., W. Gish, W. Miller, E.W. Myers, and D.J. Lipman. 1990. Basic local alignment search tool. J. Mol. Biol. 215: 403-410.

Bailey, N.T.J. 1995. Statistical methods in biology. Cambridge University Press, Cambridge, UK.

Bairoch, A., P. Bucher, and K. Hofmann. 1995. The PROSITE database, its status in 1995. Nucleic Acids Res. 24: 189-191.

Bergerat, A., B. de M assy, D. Gadelle, P.-C. Varoutas, A. N icolas, and P. Forterre. 1997. An atypical topoisomerase II from ar- 
chaea with implication for meiotic recombination. Nature 386: 414-417.

Bhargava, J., J. Engebrecht, and G.S. Roeder. 1992. The rec102 mutant of yeast is defective in meiotic recombination and chromosome synapsis. Genetics 130: 59-69.

Bishop, D. K., D. Park, L. Xu, and N. Kleckner. 1992. DM C1: A meiosis-specific yeast homolog of $E$. coli recA required for recombination, synaptonemal complex formation, and cell cycle progression. Cell 69: 439-456.

Bullard, S.A., S. Kim, A.M. Galbraith, and R.E. Malone. 1996. Double strand breaks at the HIS2 recombination hot spot in Saccharomyces cerevisiae. Proc. Natl. Acad. Sci. 93: 1305413059.

Cao, L., E. Alani, and N. Kleckner. 1990. A pathway for generation and processing of double-strand breaks during meiotic recombination in S. cerevisiae. Cell 61: 1089-1101.

Connelly, J.C. and D.R.F. Leach. 1996. The sbcC and sbcD genes of Escherichia coli encode a nuclease involved in palindrome inviability and genetic recombination. Genes Cells 1: 285291.

de Massy, B. and A. Nicolas. 1993. The control in cis of the position and the amount of the ARG4 meiotic double-strand break of Saccharomyces cerevisiae. EMBO J. 12: 1459-1466.

de Massy, B., V. Rocco, and A. Nicolas. 1995. The nucleotide mapping of DNA double-strand breaks at the CYS3 initiation site of meiotic recombination in Saccharomyces cerevisiae. EMBO J. 14: 4589-4598.

Dolganov, G.M., R.S. Maser, A. N ovikov, L. Tosto, S. Chong, D.A. Bressan, and J.H. Petrini. 1996. Human Rad50 is physically associated with human M rell: Identification of a conserved multiprotein complex implicated in recombinational DNA repair. Mol. Cell. Biol. 16: 4832-4841.

Engebrecht, J.A., K. Voelkel-M eiman, and G.S. Roeder. 1991. Meiosis-specific RN A splicing in yeast. Cell 66: 1257-1268.

Engebrecht, J., F. Klein, and J. Loidl. 1997. Genetic and morphological approaches for the analysis of meiotic chromosomes in yeast. Methods Cell Biol. (in press).

Gibson, F.P., D.R.F. Leach, and R.G. Lloyd. 1992. Identification of $s b c D$ mutations as cosuppressors of recBC that allow propagation of DNA palindromes in Escherichia coli K-12. J. Bacteriol. 174: 1222-1228.

Gietz, R.D. and A. Sugino. 1988. N ew yeast-Escherichia coli shuttle vectors constructed with in vitro mutagenized yeast genes lacking six-base pair restriction sites. Gene 74: 527534.

Gietz, D., A. St. Jean, R.A. Woods, and R. Schiestl. 1992. Improved method for high efficiency transformation of intact yeast cells. Nucleic Acids Res. 20: 1425.

Goldway, M., A. Sherman, D. Zenvirth, T. Arbel, and G. Simchen. 1993. A short chromosomal region with major roles in yeast chromosome III meiotic disjunction, recombination and double strand breaks. Genetics 133: 159-169.

Ivanov, E.L., V.G. Korolev, and F. Fabre. 1992. XRS2, a DNA repair gene of Saccharomyces cerevisiae, is needed for meiotic recombination. Genetics 132: 651-664.

Ivanov, E.L., N. Sugawara, J. Fishman-Lobell, and J.E. Haber. 1996. Genetic requirements for the single-strand annealing pathway of double-strand break repair in Saccharomyces cerevisiae. Genetics 142: 693-704.

Johzuka, K. and H. Ogawa. 1995. Interaction of Mrell and Rad50: Two proteins required for DNA repair and meiosisspecific double-strand break formation in Saccharomyces cerevisiae. Genetics 139: 1521-1532.

Kane, S.M. and R. Roth. 1974. Carbohydrate metabolism during ascospore development in yeast. J. Bacteriol. 118: 8-14.

Keeney, S. and N. Kleckner. 1995. Covalent protein-DN A com- plexes at the $5^{\prime}$ strand termini of meiosis-specific doublestrand breaks in yeast. Proc. Natl. Acad. Sci. 92:1127411278.

Keeney, S., C.N. Giroux, and N. Kleckner. 1997. Meiosis-specific DNA double-strand breaks are catalyzed by Spoll, a member of a widely conserved protein family. Cell 88: 375384.

Klein, F., A. Karwan, and U. Wintersberger. 1990. Pedigree analyses of yeast cells recovering from DNA damage allow assignment of lethal events to individual post-treatment generations. Genetics 124: 57-65.

Liu, J., T.C. Wu, and M. Lichten. 1995. The location and structure of double-strand DNA breaks induced during yeast meiosis: Evidence for a covalently linked DNA-protein intermediate. EMBO J. 14: 4599-4608.

Loidl, J., K. Nairz, and F. Klein. 1991. Meiotic chromosome synapsis in a haploid yeast. Chromosoma 100: 221-228.

Loidl, J., F. Klein, and H. Scherthan. 1994. Homologous pai ring is reduced but not abolished in asynaptic mutants of yeast. J. Cell. Biol. 125: 1191-1200.

Lupas, A., M. van Dyke, and J. Stock. 1991. Predicting coiled coils from protein sequences. Science 252: 1162-1164.

Lydall, D., Y. Nikolsky, D.K. Bishop, and T. Weinert. 1996. A meiotic recombination checkpoint controlled by mitotic checkpoint genes. Nature 383: 840-843.

Malone, R.E. and R.E. Esposito. 1981. Recombinationless meiosis in Saccharomyces cervisiae. Mol. Cell. Biol. 1: 891-901.

McKee, A. and N. Kleckner. 1997. A general method for identifying recessive diploid-specific mutations in Saccharomyces cerevisiae, its application to the isolation of mutants blocked at intermediate stages of meiotic prophase and characterization of a new gene SAE2. Genetics 146: 797-816.

Menees, T. M., P.B. Ross-M acDonald, and G.S. Roeder. 1992. $\mathrm{MEI}$, a meiosis-specific yeast gene required for chromosome synapsis. Mol. Cell. Biol. 12: 1340-1351.

Moore, J.K. and J.E. Haber. 1996. Cell cycle and genetic requirements of two pathways of nonhomologous end-joining repair of double-strand breaks in Saccharomyces cerevisiae. Mol. Cell. Biol. 16: 2164-2173.

Nairz, K. 1997. "mrel1S-A new yeast mutation that blocks double-strand break processing and leads to nonhomologous synapsis," Ph.D. thesis. University of Vienna, Austria.

Ogawa, H., K. Johzuka, T. N akagawa, S.H. Leem, and A.H. Hagihara. 1995. Functions of the yeast meiotic recombination genes, MRE11 and MRE2. Adv. Biophys. 31: 67-76.

Orr-Weaver, T.L., J.W. Szostak, and R.J. Rothstein. 1983. Genetic applications of yeast transformation with linear and gapped plasmids. Methods Enzymol. 101: 228-245.

Padmore, R., L. Cao, and N. Kleckner. 1991. Temporal comparison of recombination and synaptonemal complex formation during meiosis in S. cerevisiae. Cell 66: 1239-1256.

Petrini, J.H., M.E. Walsh, C. Di Mare, X.N. Chen, J.R. Korenberg, and D.T. Weaver. 1995. Isolation and characterization of the human M RE11 homologue. Genomics 29: 80-86.

Prinz, S., A. Amon, and F. Klein. 1997. Isolation of COM1, a new gene required to complete mei otic double-strand break induced recombination in S. cerevisiae. Genetics 146: 781795.

Rocco, V. and A. Nicolas. 1996. Sensing of DNA non-homology lowers the initiation of meiotic recombination in yeast. Genes Cells 1: 645-661.

Rockmill, B., J.A. Engebrecht, H. Scherthan, J. Loidl, and G.S. Roeder. 1995a. The yeast MER2 gene is required for chromosome synapsis and the initiation of meiotic recombination. Genetics 141: 49-59.

Rockmill, B., M. Sym, H. Scherthan, and G.S. Roeder. 1995b. 


\section{Nairz and Klein}

Roles for two RecA homologs in promoting meiotic chromosome synapsis. Genes \& Dev. 9: 2684-2695.

Rose, M.D., F. Winston, and P. Hieter. 1990. Methods in yeast genetics. A laboratory course manual. Cold Spring Harbor Laboratory Press. Cold Spring Harbor, NY.

Rothstein, R.J. 1983. One step gene disruption in yeast. Methods Enzymol. 101: 202-211.

Sambrook, J., E.F. Fritsch, and T. Maniatis. 1989. Molecular cloning: A laboratory manual. Cold Spring Harbor Laboratory Press, Cold Spring Harbor, NY.

Sanger, F., S. Nicklen, and A.R. Coulson. 1977. DNA sequencing with chain-terminating inhibitors. Proc. Natl. Acad. Sci. 83: 735-739.

Scherthan, H., J. Loidl, T. Schuster, and D. Schweizer. 1992. M eiotic chromosome condensation and pairing in Saccharomyces cerevisiae studied by chromosome painting. Chromosoma 101: 590-595.

Seifert, H.S., E.Y. Chen, M. So, and F. Heffron. 1986. Shuttle mutagenesis: A method of transposon mutagenesis for Saccharomyces cerevisiae. Proc. Natl. Acad. Sci. 83: 735-739.

Sharples, G.J. and D.R. Leach. 1995. Structural and functional similarities between the SbcCD proteins of Escherichia coli and the RAD50 and M RE11 (RAD32) recombination and repair proteins of yeast [letter]. Mol. Microbiol. 17: 1215-1217.

Sherman, F. and H. Roman. 1963. Evidence for two types of allelic recombination in yeast. Genetics 48: 255-261.

Sikorsky, R.S. and P. Hieter. 1989. A system of shuttle vectors and yeast host strains designed for efficient manipulation of DN A in Saccharomyces cerevisiae. Genetics 122: 19-27.

Smith, R.F., B.A. Wiese, M.K. Wojzynski, D.B. Davison, and K.C. Worley. 1996. BCM Search Launcher-An integrated interface to molecular biology data base search and analysis services available on the World Wide Web. Genome Res. 6: 454-462.

Storlazzi, A., L. Xu, L. Cao, and N. Kleckner. 1995. Crossover and noncrossover recombination during meiosis: Timing and pathway relationships. Proc. Natl. Acad. Sci. 92: 85128516.

Sym, M., J.A. Engebrecht, and G.S. Roeder. 1993. ZIP1 is a synaptonemal complex protein required for meiotic chromosome synapsis. Cell 72: 365-378.

Tavassoli, M., M. Shayeghi, A. N asim, and F.Z. Watts. 1995. Cloning and characterisation of the Schizosaccharomyces pombe rad32 gene: $A$ gene required for repair of double strand breaks and recombination. Nucleic Acids Res. 23: 383-388.

Tsukamoto, Y., J. Kato, and H. Ikeda. 1996. Effects of mutations of RAD 50, RAD51, RAD52, and rel ated genes on illegitimate recombination in Saccharomyces cerevisiae. Genetics 142: 383-391.

Wagstaff, J.E., S. Klapholz, and R.E. Esposito. 1982. Meiosis in haploid yeast. Proc. Natl. Acad. Sci. 79: 2986-2990.

Weiner, B.M. and N. Kleckner. 1994. Chromosome pairing via multiple interstitial interactions before and during meiosis in yeast. Cell 77: 977-991.

Xu, L. and N. Kleckner. 1995. Sequence non-specific doublestrand breaks and interhomolog interactions prior to doublestrand break formation at a meiotic recombination hot spot in yeast. EMBO J. 14: 5115-5128. 


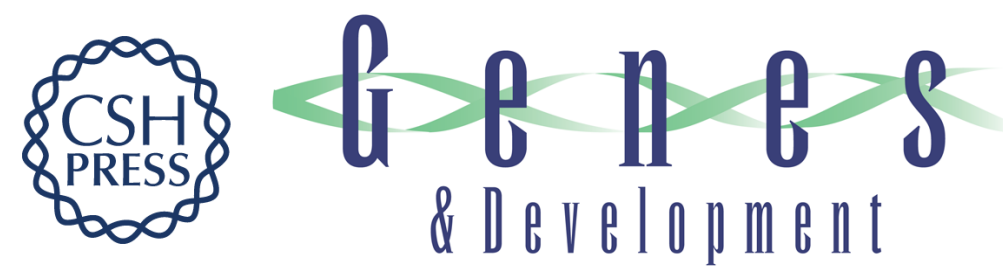

\section{mre11S-a yeast mutation that blocks double-strand-break processing and permits nonhomologous synapsis in meiosis}

Knud Nairz and Franz Klein

Genes Dev. 1997, 11:

Access the most recent version at doi:10.1101/gad.11.17.2272

References

This article cites 56 articles, 28 of which can be accessed free at:

http://genesdev.cshlp.org/content/11/17/2272.full.html\#ref-list-1

License

Email Alerting

Receive free email alerts when new articles cite this article - sign up in the box at the top

Service right corner of the article or click here.

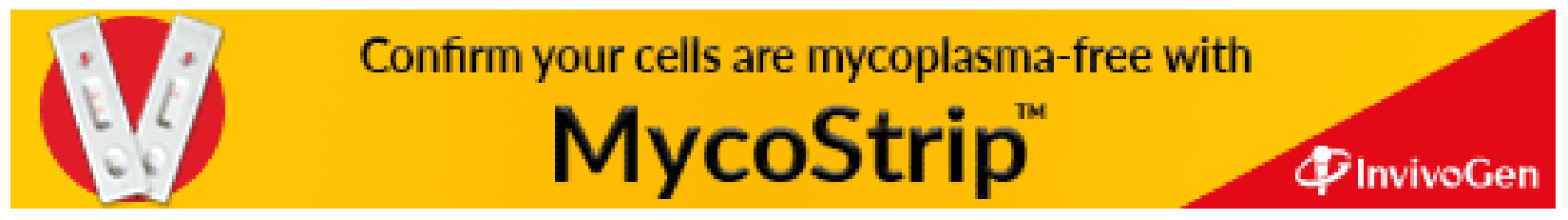

